
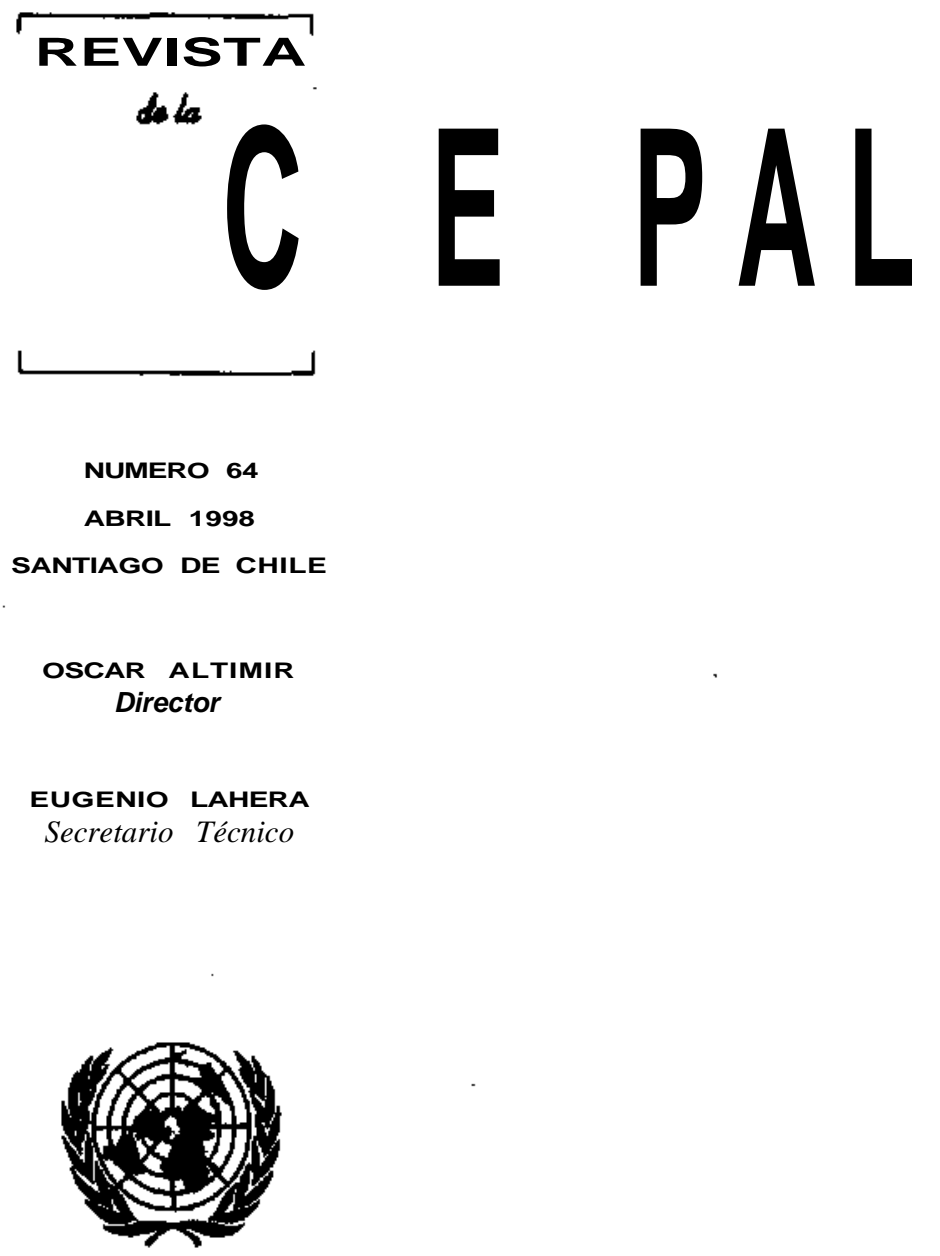

NACIONES UNIDAS 
Instituciones y crecimiento ¿Puede el capital humano ser un vínculo?

Nauro Campos y Jeffrey B. Nugent

Flujos de capital externo en América Latina y el Caribe en los años noventa: experiencias y políticas

Gunther Held y Raquel Szalachman

El Banco Central y la política macroeconómica de Chile en ios años noventa

Roberto Zahler

Política fiscal, ciclo y crecimiento

Ricardo Mariner

La convergencia hacia mejores prácticas productivas y de políticas: el acuerdo de la OMC sobre medidas de inversión vinculadas al comercio

Francisco Sercovich

Efectos para América Latina de la expansión de la Unión Europea

Peter Nunnenkamp

La dimensión Norte-Sur de las industrias de limpieza ambiental

y la difusión de tecnologías limpias

Jonathan R. Barton

La evolución del papel del Estado en la regulación del transporte terrestre

lan Thomson

Manejo integrado del recurso agua, con la perspectiva de los

Principios de Dublin

Miguel Solanes

Publicaciones recientes de la CEPAL 


\section{El Banco Central y la política macroeconómica de Chile en los años noventa}

\section{Roberto Zahler}

Ex Presidente del

Banco Central de Chile
Este artículo tiene por objetivo describir y analizar la formulación, ejecución y resultados de la política macroeconómica llevada a cabo por el Banco Central de Chile en el primer quinquenio de los años noventa. En la sección I se explica la importancia de los equilibrios macroeconómicos desde la perspectiva del Banco Central de Chile. En la sección II se describen los objetivos del Banco Central y como éste interpretó el logro de los equilibrios interno y externo. La sección III resume las características institucionales, estructurales y coyunturales que le dan la particularidad del caso a la experiencia chilena. En la sección IV se exponen los criterios con que se formuló y llevó a cabo la política macroeconómica por parte del instituto emisor. En la sección V se describe y explica lo esencial de las políticas monetaria, cambiaría, de reservas internacionales y de apertura de la cuenta de capitales llevadas a cabo durante el período. Finalmente, la sección VI describe los resultados más importantes de las políticas anteriores y resume las principales conclusiones de este estudio, 


\section{Los equilibrios macroeconómicos básicos}

Uno de los temas de mayor significación en el diseño de la política económica lo constituye el papel que desempeña la mantención de los equilibrios macroeconómicos en el proceso de crecimiento económico. Las políticas fiscal, monetaria, cambiaría, salarial y financiera son claves para alcanzar y preservar los macroequilibrios fundamentales de la economía, tanto en lo concerniente al empleo, la estabilidad de precios y del sistema de pagos -el equilibrio interno-, como en lo atingente al equilibrio del sector externo.

A fin de alcanzar y preservar el equilibrio interno, el nivel de uso de los recursos productivos del país ha de ser tal que no se generen presiones inflacionarias adicionales a las programadas. Para ello es necesario que la política macroeconómica, y en especial la monetaria y la fiscal, tengan como orientación fundamental cautelar que la demanda interna agregada se encuentre alineada con el potencial productivo (oferta agregada) de la economía.

$\mathrm{Si}$ bien es cierto que, como tendencia, el gasto global no debe crecer más que el producto potencial ${ }^{1}$ -expansión estimada en torno al $6.5 \%$ real anual para la economía chilena durante el primer quinquenio de los años noventa- ${ }^{2}$ es posible y conveniente complementar en forma adecuada el ahorro interno con recursos de origen externo en el financiamiento de la inversión. Esto último hace deseable que el nivel del gasto interno exceda al ingreso nacional en una fracción que dependerá del monto, naturaleza y sustentabilidad de las fuentes de financiamiento externo. Para el caso de la economía chilena se estimó que la preservación del equilibrio externo equivalía a acomodar un déficit de tendencia en la cuenta corriente de la balanza de pagos en el rango de $3 \%$ a $4 \%$ del PIB. ${ }^{3}$

El autor agradece los comentarios de Héctor Assael, Gunther Held y Andras Uthoff.

${ }^{1}$ En rigor, esta afirmación es válida cuando la economía se encuentra en la frontera de producción. Cuando está por debajo, puede crecer a un ritmo mayor (si la restricción externa lo permite). Pero cuando la economía se encuentra sobrecalentada, es preciso ajustar los niveles de actividad, por lo que durante ese tiempo el gasto debe crecer a un ritmo menor que el producto potencia!.

${ }^{2}$ Véase P. Rojas, E. López, y S. Jiménez, "Determinantes del crecimiento del producto potencial de Chile: el rol del comercio", en Análisis empírico del crecimiento en Chile, 1997, F. Morandé y R. Vergara (eds.) CEP/LADES-Georgetown, Santiago de Chile, junio.

${ }^{3}$ Véase N. Eyzaguirre y P. Rojas, "Las políticas monetaria y cambiaría en Chile durante los noventa", Santiago de Chile, Banco Central de Chile, enero de 1995.
Una baja tasa de inflación es esencial cuando se intenta alcanzar metas ambiciosas de crecimiento económico, inversión, empleo y reducción de la pobreza. Dado que el Banco Central no tiene los instrumentos directos para el logro de estos objetivos, debe concentrar sus esfuerzos tanto en disminuir la tasa de inflación como en avanzar hacia una mayor estabilidad del nivel de precios; sólo de esa manera puede contribuir en forma efectiva a la consecución de tales objetivos y, por ende, al desarrollo del país. Cabe destacar que la estabilidad de precios no es un objetivo fácil de alcanzar, sobre todo en un país con historia de inflación crónica, como Chile, y con varios decenios de vigencia de muy generalizados mecanismos de indexación de precios. Además, en la primera mitad de los años noventa la economía chilena operó, para todos los efectos prácticos, a pleno empleo y sin capacidad productiva ociosa.

Un entorno macroeconómico que garantice una inflación controlada primero, luego decreciente y finalmente estabilizada a una tasa baja, es un requisito previo para alcanzar elevados ritmos de inversión y aumentos sostenidos en el empleo y en la productividad de los factores. Sin embargo, la experiencia ha demostrado que reducir la inflación desde tasas muy elevadas a tasas moderadamente bajas es la parte más fácil del proceso de estabilización. Lo más difícil es lograr una convergencia hacia las tasas de inflación que registran los países industrializados. Ello requiere un esfuerzo perseverante por configurar condiciones que conduzcan a un proceso sostenido de desaceleración inflacionaria y que, simultáneamente, permitan minimizar la presencia de distorsiones que induzcan fluctuaciones indeseadas, cuando no reversiones, de dicho proceso. Los requisitos necesarios para alcanzar ese resultado son, entre otros, la mantención de un control severo sobre las finanzas públicas, que evite la amplificación de los ciclos de gasto; una política monetaria que permita la existencia de tasas de interés reales consistentes con la productividad del capital en el largo plazo; un tipo de cambio real que asegure una adecuada competitividad del sector transable y que al mismo tiempo permita una utilización de ahorro externo consistente con la viabilidad de la balanza de pagos en el mediano plazo; y una política financiera que asegure la estabilidad y solvencia del sistema financiero, de 
modo de prevenir y evitar que su eventual mal funcionamiento, fragilidad y, por cierto su crisis, tengan repercusiones de naturaleza macroeconómica.

Ciertamente sería una exageración pretender que la estabilidad macroeconómica es una condición suficiente para lograr tasas de crecimiento altas y sostenidas. Otros elementos de carácter más estructural, vinculados al funcionamiento competitivo y flexible de los mercados, especialmente en el de los factores productivos, así como las políticas que regulan la estructura y funcionamiento de algunos mercados claves, como el financiero o los mercados monopólicos, y las que afectan el proceso de ahorro e inversión, la formación de capital humano y la investigación científica y tecnológica, son también condiciones determinantes para generar y dinamizar el crecimiento económico.

Los criterios expuestos en esta definición de entorno macroeconómico no son fáciles de medir. Por ello suele haber discusión sobre si los niveles de la tasa de interés, del tipo de cambio o del saldo de la cuenta corriente de la balanza de pagos son los apropiados en cada período y, en consecuencia, se torna difícil juzgar si hay o no desviaciones respecto de las condiciones de equilibrio macroeconómico en una perspectiva de mediano plazo. Este problema de diagnóstico se hace más complejo en la medida en que la economía es más estable y los objetivos antiinflacionarios más ambiciosos. En efecto, las condiciones de inestabilidad macroeconómica que generan una inflación del orden de $30 \%$ anual o más son fácilmente identificables, pero las que representan desvíos marginales respecto de un objetivo de inflación bajo, como el que fue teniendo Chile hacia finales de la primera mitad de los años noventa, son materia de discusión y controversia. La prudencia, el buen criterio, la observación cuidadosa, la comparación con las experiencias de otros países y la independencia de juicio son activos muy importantes para efectuar un diagnóstico macroeconómico adecuado en tales circunstancias.

La dificultad de definir con precisión cuál es el entorno coherente con la estabilidad macroeconómica es precisamente lo que lleva, en la práctica, a que sea la propia tasa de inflación uno de los principales indicadores para evaluar la habilidad de las autoridades económicas en el control de dicho entorno.

Pero no sólo es importante la inflación de un período determinado, sino también su sostenibilidad en el tiempo. Es obvio que las autoridades que recurrentemente permiten tasas elevadas de inflación no tienen un control adecuado de la situación económica; los agentes económicos terminan incorporando un factor de desconfianza e incertidumbre en sus pautas de comportamiento, que les hace percibir que, de alguna manera y en algún momento, será necesario efectuar un ajuste del gasto. Sin embargo, también es posible encontrar situaciones de baja inflación en las que las políticas tampoco son sostenibles. Estos casos, que se caracterizan por significativos déficit fiscales o en cuenta corriente de la balanza de pagos, usualmente han sido seguidos por la reaparición repentina del problema inflacionario latente. ${ }^{4}$ En estas situaciones los déficit fiscales y de cuenta corriente son indicadores útiles para anticipar que, la mayoría de las veces, las bajas tasas de inflación observadas no son sostenibles. en el tiempo.

Sólo aquellos casos en los que el Banco Central y las autoridades económicas del gobierno han podido crear un ambiente de baja inflación -en su nivel o tendencia- en forma sostenida, han sido exitosos y por lo tanto capaces de generar expectativas de que las políticas macroeconómicas en vigencia serán mantenidas, o a lo más modificadas en forma gradual y paulatina, en caso de ser necesario.

En síntesis, los resultados en términos de inflación y la implementación de políticas coherentes con las metas planteadas en esta materia son fundamentales para alcanzar la credibilidad en la política económica. Dicha credibilidad, a su vez, incentiva el proceso de ahorro y estimula la inversión, iniciativa e innovación empresarial, con todo su impacto positivo sobre la creación de empleos y el crecimiento económico.

\section{II}

\section{Los objetivos de la política}

La Ley Orgánica Constitucional del Banco Central de Chile define tres objetivos para el instituto emisor: velar por la estabilidad de la moneda, por el normal funcio-

\footnotetext{
${ }^{4}$ Cabe señalar que hay algunos casos de déficit fiscales moderados que, en presencia de mercados de capitales desarrollados y profundos, no necesariamente son fuente de presiones inflacionarias.
} 
namiento de los pagos internos, y por el de los pagos externos. La ley también señala que el Banco Central, al adoptar sus acuerdos, debe tener presente la orientación general de la política económica del gobierno. Durante los años noventa el Banco Central de Chile centró sus objetivos en la reducción gradual, sistemática y sostenible de la tasa de inflación, en acotar un rango dentro del cual debiera situarse el déficit de la cuenta corriente de la balanza de pagos y en crear las condiciones que garantizaran la estabilidad y solidez del sistema financiero interno. ${ }^{5}$

En consecuencia, la formulación y ejecución de las políticas del Banco Central no estuvieron orientadas directamente a la consecución de otros objetivos de la política económica del gobierno, tales como dinamizar el crecimiento económico, aumentar el ahorro y el empleo o mejorar la distribución del ingreso. Y ello por tres razones: de un lado, porque sus objetivos están acotados por la ley; en segundo lugar, porque los instrumentos de que dispone el Banco Central son limitados, al punto que hay quienes sostienen que el instituto emisor no poseería la capacidad necesaria para el logro de los tres objetivos fijados por la ley; y, en tercer lugar, porque la consecución de estos objetivos se encaró de manera que ella fuera funcional a la estrategia global de desarrollo del gobierno, de crecimiento económico con equidad.

Los objetivos legales del Banco Central de Chile se llevaron a la práctica en el entendido de que ellos se definirían en un horizonte temporal prolongado, de modo que su consecución fuese dándose a lo largo del tiempo y de un modo sostenible. Con ello se contribuiría a otorgar credibilidad a la política macroeconómica y estabilidad y dinamismo sostenible al proceso de desarrollo. De otro lado, una característica fundamental de la forma que se entendieron los objetivos del Banco Central fue que ellos debían lograrse en un contexto equilibrado, sin generar traumatismos en otras áreas claves de la economía y sin que fuera necesario,

\footnotetext{
${ }^{5}$ Este trabajo examina la experiencia del Banco Central de Chile solamente en relación con los dos primeros objetivos: el control de la inflación y el mantenimiento del equilibrio extemo de la economía chilena. Sin embargo, parte importante del éxito alcanzado en el logro de esos dos objetivos ha descansado en la creación de condiciones, en el cuidado y en el seguimiento de la solvencia del sistema financiero interno. Aún cuando excede el propósito de este trabajo, la opción por el "desarrollo financiero" (incluyendo, además de la banca, a los intermediarios financieros no bancarios y su adecuada supervisión y regulación, en contraste con las políticas más ingenuas de "liberalización financiera") ha desempeñado un importante papel en la creación de un marco macroeconómico e institucional favorable a una política económica coherente.
}

y ni siquiera deseable, mostrar logros espectaculares e inmediatos. Por el contrario, se privilegió la persistencia, sistematicidad, solidez, estabilidad y credibilidad, así como el equilibrio macroeconómico global, con todo su impacto positivo sobre las decisiones de ahorro e inversión, el empleo y los salarios, en una suerte de círculo virtuoso del proceso de desarrollo económico. La alternativa habría sido mostrar el logro aparentemente rápido y muy exitoso, cuando no espectacular, de unos pocos objetivos, pero a costa de haber generado grandes desajustes en otras áreas claves de la economía o de la sociedad. La experiencia demuestra que logros de esta índole se caracterizan por su fragilidad y escasa perdurabilidad en el tiempo, con la consecuente necesidad de frenar, cuando no revertir, la orientación de las reformas y la ejecución de las políticas, afectando así la confianza de los agentes y la eficacia y los fundamentos del programa macroeconómico.

\section{El objetivo antiinflacionario}

La Ley Orgánica Constitucional del Banco Central de Chile establece en su artículo tercero que uno de los objetivos del instituto emisor es velar por la estabilidad del valor de la moneda. Es decir, la ley impone como objetivo la estabilidad de precios, lo que en la primera mitad de los años noventa se interpretó como la reducción sistemática y sostenible de la tasa de inflación, y el logro de una tasa de un dígito. ${ }^{6}$

Muchas veces se cuestiona la prioridad asignada al objetivo de la estabilidad de precios, argumentándose que lo verdaderamente importante es el desarrollo económico y que, por lo tanto, la política monetaria debería estar subordinada a ese objetivo. Ese tipo de críticas es más frecuente en períodos o situaciones en que la lucha contra la inflación, reflejada en una política monetaria calificada como restrictiva, produce una desaceleración en el ritmo de crecimiento de la economía.

Sin embargo, estudios empíricos sobre la relación entre la inflación y el crecimiento, realizados sobre la base de información para países en desarrollo, sugieren que, siendo todo lo demás constante, una mayor tasa de inflación implica una menor tasa de crecimiento de largo plazo. Esta relación resulta ser aún más sig-

\footnotetext{
${ }^{6}$ El objetivo del Banco Central fue llevar la tasa de inflación al nivel de la de los países industriales, es decir, entre $2 \%$ y $3 \%$ al año. Sin embargo, ese equilibrio final pasaba por reducir la inflación a niveles de un dígito hacia 1995-1996, para acercarse luego gradualmente al rango señalado.
} 
nificativa en aquellos países con inflaciones moderadas y altas. De un modo similar, los mismos estudios empíricos demuestran también que en países con tasas de inflación bajas y estables — de alrededor de un dígito- las variaciones en ellas tenderían a no afectar severamente la tasa de crecimiento económico.

El objetivo de estabilidad de precios, que por lo demás es común a casi todos los bancos centrales del mundo $-\mathrm{y}$ ciertamente a los que son independientes como el chileno-, no es un fin en sí mismo. Es evidente que el objetivo principal de las autoridades económicas en su conjunto es lograr un mayor desarrollo del país y mejorar las condiciones y calidad de vida de la población, para lo cual es condición necesaria un elevado crecimiento económico. Sin embargo, esto no se contrapone al logro del objetivo antiinflacionario. Por el contrario, está demostrado tanto teórica como empíricamente que la estabilidad de precios favorece el crecimiento económico en el mediano y largo plazo. El Banco Central de los Estados Unidos, por ejemplo, publicó hace poco tiempo un estudio en que se demuestra que una menor inflación aumenta la productividad de la economía. Más aún, la inflación es de hecho un impuesto (no legislado) regresivo, ya que afecta más fuertemente a la gente de menores recursos, que es la que tiene menos posibilidades de protegerse de ella. Por lo tanto, la estabilidad de precios tiene también un efecto positivo sobre la distribución del ingreso y ayuda a lograr una sociedad con mayores oportunidades. Así entonces, una institución como el Banco Central, que vela por el logro del objetivo antiinflacionario, colabora y contribuye al desarrollo económico de mediano y largo plazo del país.

Durante los años noventa el Banco Central de Chile ha planteado que la estabilidad de precios es una condición necesaria para un progreso económico rápido y sostenido, y que la experiencia internacional así lo demuestra. Desde esta perspectiva, dicha estabilidad es sólo un medio para el logro de un fin más global, como lo es un buen desempeño económico. Un objetivo ambicioso, pero alcanzable y razonable en el caso de la economía chilena, es el de llegar a tasas de inflación anuales bajas y estables, como las que se registran actualmente en los países desarrollados. Es indudable que lo óptimo sería vivir en un mundo sin inflación. Sin embargo, las rigideces que se enfrentan en la realidad pueden hacer necesaria la ocurrencia de un lento aumento en el nivel de precios de la economía, aunque a tasas muy bajas, para facilitar algunos ajustes en la estructura de los precios relativos. También las mejoras en la calidad de los bienes y servicios conllevan una tendencia al alza estadística en el nivel de precios. No obstante, una tasa de inflación anual estable como la que registran los países industriales podría ser calificada, sin riesgo de exageración, como inofensiva, toda vez que los graves problemas asociados con la inflación tienden a desaparecer a medida que el ritmo inflacionario entra en ese rango.

El objetivo de alcanzar una tasa de inflación similar a la de los países desarrollados se justifica, además, por cuanto la estrategia de internalización de la economía chilena se hace mucho más eficiente en un contexto de estabilidad interna de precios. Asimismo, el hecho de que el sector público consolidado, incluidas las cuentas del Banco Central, no registre déficit, unido a la creciente solidez del desempeño macroeconómico de Chile, indican que no hay razones para tener tasas de inflación superiores a las internacionales. Cabe destacar, eso sí, que la generalizada indexación de la economía chilena sobre la base de la inflación pasada sugiere la conveniencia de avanzar gradualmente hacia el objetivo de estabilidad de precios. En efecto, de esa forma se minimizan los costos de corto plazo en términos de actividad económica y empleo vinculados a la política de estabilización de precios, a la vez que la autoridad económica va ganando credibilidad a jo largo del tiempo. Ello tiende a dar creciente legitimidad a la política antiinflacionaria y permite perfeccionar la política monetaria, haciéndola más eficiente, sin sacrificar innecesariamente otros objetivos de la política económica.

\section{El objetivo de equilibrio externo}

La Ley Orgánica Constitucional del Banco Central de Chile también establece en su artículo tercero que otro de los objetivos del instituto emisor es asegurar el normal desenvolvimiento de los pagos externos. Es decir, la ley impone como objetivo el logro del equilibrio externo, lo que se interpretó como una afirmación de que el déficit en la cuenta corriente de la balanza de pagos importa, y de que es necesario asegurar que dicho déficit esté dentro de un rango preestablecido. $^{7}$

\footnotetext{
${ }^{7}$ En el caso de Chile, dicho rango se determinó, de un lado, porque se estimó que el producto potencial en dólares, con un tipo de cambio real constante, crece en torno a $8 \%$ por año. De otro lado, como a comienzos de 1990 la deuda externa era levemente superior a $50 \%$ del PIB, un déficit en cuenta corriente de la balanza de pagos de (máximo) 4\% del PIB implica que la razón deuda externa/pis se mantendría constante. E! rango adoptado, entre 3\% y $4 \%$ del PIB, significó que no se quiso pasar el límite de 50\% del PIB de endeudamiento externo; por el contrario, se estimó prudente disminuirlo gradualmente, lo que efectivamente ocurrió.
} 
Con frecuencia se objeta que se dé tanta importancia al déficit en la cuenta corriente de la balanza de pagos en el diseño de la política macroeconómica. Suele sostenerse que los países en desarrollo requieren del ahorro externo para el financiamiento de la inversión, y que aquel déficit no tendría mayor importancia si su financiamiento proviniera de entradas netas de capitales "privadas" y "voluntarias". De otro lado, se argumenta que el déficit no sería preocupante en aquellos casos en que el exceso de importaciones se concentrara en los bienes de capital, sobre todo si éstos se orientaran a aumentar la capacidad productiva del sector transable de la economía.

$\mathrm{Si}$ bien las consideraciones anteriores tienen cierta validez, ellas son de menor significación frente a lo que verdaderamente importa: los límites tolerables, tanto en magnitud como en persistencia, del déficit en la cuenta corriente de la balanza de pagos. El énfasis en este déficit, que no es más que un reflejo del exceso de gasto interno sobre el ingreso de la economía y, más específicamente, el énfasis en el control del déficit de tendencia de la cuenta corriente de la balanza de pagos, se justifican por el influjo determinante que ha tenido históricamente la restricción externa -incluidos el impacto de la evolución de los términos del intercambio y de las tasas de interés internacionales, entre otros factores de la inserción de Chile en la economía internacional- sobre la vulnerabilidad de la economía chilena.

Además, centrar la atención en la trayectoria del déficit en la cuenta corriente de la balanza de pagos es otra forma de estar atentos a que el ahorro externo no sustituya sino que complemente el ahorro interno, de modo que este último financie un porcentaje elevado y significativo de la inversión interna, lo que es un factor determinante de la estabilidad y sustentabilidad del crecimiento económico.

De la mayor importancia en el diseño y la ejecución de la política macroeconómica chilena en la primera mitad de los años noventa fue el hecho de que el Banco Central siempre resistió la tentación de relajar la política monetaria antes de tiempo, a pesar de las holguras disponibles en el sector externo; estas últimas provinieron tanto de la muy favorable evolución de las exportaciones, que crecieron en volumen a una tasa media anual de $10 \%$, como de la significativa entrada neta de capitales externos, que alcanzó a un promedio de $6 \%$ del PIB. Cabe destacar que en ese período hubo fuertes presiones para que se relajara la política monetaria (disminuyendo la tasa de interés interna) y se modificara, cuando no eliminara, la política de banda cambiaría vigente, la de reservas internacionales, y también la diseñada para enfrentar los flujos financieros externos de corto plazo, todo lo cual hubiera inducido a una mayor apreciación del peso chileno que la efectivamente registrada durante ese período. Sin embargo, un sello distintivo de la política macroeconómica de esos años fue definir y defender clara y firmemente la estrategia global, manteniendo la instancia de la política monetaria todo lo necesario como para avanzar seria y fundadamente en el control de la inflación, y no permitiendo un déficit mayor que el predefinido en la cuenta corriente de la balanza de pagos. De ese modo el Banco Central contribuyó a consolidar un crecimiento económico elevado para Chile, financiado prioritariamente con ahorro interno, y en el proceso aseguró una baja gradual, pero creíble, sostenida y sostenible de la inflación, sin poner en riesgo el equilibrio externo de mediano y largo plazo de la economía chilena.

En consecuencia, independientemente de cuál fuera el "responsable" del exceso de gasto interno (el sector público o el privado), la fuente de su financiamiento (afluencia de financiamiento externo voluntario o expansión del crédito interno), la composición de las importaciones (bienes de consumo o de inversión), o el destino de estos últimos (ampliar la capacidad productiva del sector transable o no transable de la economía), para la política macroeconómica chilena de la primera mitad de los años noventa lo determinante fue crear las condiciones que impidieran generar un déficit en cuenta corriente de la balanza de pagos que cuestionara la sustentabilidad y la credibilidad de la política macroeconómica.

Aun cuando el monto preciso del déficit en cuenta corriente que conviene a un país en desarrollo es difícil de precisar, y puede variar de un país a otro o cambiar en un mismo país a lo largo del tiempo, el rango antes mencionado, de $3 \%$ a $4 \%$ del PIB para Chile a comienzos de los años noventa, surgió de tres criterios ordenadores.

En primer lugar, un déficit tendencial importante en la cuenta corriente de la balanza de pagos permitía mantener estables o mejorar levemente los indicadores habituales de solvencia externa como, por ejemplo, la deuda externa en relación al PIB O a las exportaciones de bienes y servicios.

En segundo lugar, dado un nivel considerado deseable de reservas internacionales netas, un déficit en cuenta corriente de la balanza de pagos de ese orden de magnitud se asimilaba a las proyecciones de la oferta de financiamiento externo neto de mediano y largo plazo disponible para Chile. 
Por último, la tolerancia de niveles de déficit en cuenta corriente significativamente superiores, aunque se estimen financiables durante un cierto período de tiempo, deja a la economía expuesta o vulnerable a cambios en las condiciones de liquidez o las expectativas de los mercados financieros internacionales. Es- tas pueden sufrir repentinos vuelcos por diversos tipos de perturbaciones, desde aquellas de naturaleza política hasta otras como caídas significativas en la relación de precios del intercambio para las economías de la región o alzas en las tasas de interés de los países industriales.

\section{III}

\section{Condiciones iniciales}

Algunas características estructurales de la economía, así como las condiciones coyunturales iniciales y el contexto institucional en que se llevó a cabo la política macroeconómica de los años noventa, tienen gran importancia, por cuanto definen y acotan ciertas especificidades propias que debió enfrentar esa política en el caso chileno.

\section{a) Reformas estructurales}

A comienzos de los años noventa la economía de Chile funcionaba desde hacía varios años con un esquema dentro del cual se habían realizado diversas reformas estructurales, entre ellas una rebaja y simplificación del régimen arancelario, la privatización y cambio radical del sistema de seguridad social, la liberalización y una nueva legislación para el sistema bancario, la reforma fiscal y la privatización de un gran número de empresas públicas. Muchas de estas reformas tuvieron serios reveses a lo largo del tiempo, pero por lo general la tendencia fue a reformularlas y perfeccionarlas, más que a revertirías.

\section{b) Creciente apertura externa}

La economía chilena es pequeña y bastante abierta al comercio y a las finanzas internacionales. Durante el primer quinquenio de los años noventa esta característica se profundizó. En efecto, el coeficiente de exportaciones de bienes y servicios como proporción del PIB se elevó a más del 35\%, se rebajaron los aranceles de $15 \%$ a $11 \%$; se liberaron crecientemente, hasta su totalidad, los retornos y las liquidaciones de los exportadores chilenos, y se activaron varios acuerdos bilaterales de libre comercio.

En el plano financiero también se generó una creciente apertura externa, tanto en lo relativo a la salida como a la entrada de capitales. La inversión de chilenos en el exterior, con la sola excepción de ban- cos, administradoras de fondos previsionales, compañías de seguros y fondos mutuos, se liberalizó completamente. En el caso de estas instituciones, la liberalización fue más gradual y selectiva, tanto por restricciones de tipo legal como por otras de carácter prudencial, impulsadas principalmente por el Banco Central. También hubo una creciente liberalización de la salida de capitales de no residentes. Así por ejemplo, se disminuyó de tres años a un año el plazo mínimo para repatriar capitales de inversiones extranjeras, se liberalizó totalmente la salida de inversiones al amparo del capítulo XIX del Compendio de Normas de Cambios Internacionales ${ }^{8}$ y se liberalizó el prepago de deudas con el exterior, así como el porcentaje mínimo de crédito externo que debía acompañar a la inversión externa directa.

En cuanto a la entrada de capitales, se registró un significativo aumento de la inversión extranjera directa y se autorizaron y desarrollaron nuevos mecanismos tales como ADR (American Depository Receipts), bonos y bonos convertibles en acciones, cuyas condiciones también fueron liberalizadas a lo largo del tiempo. Debido al impacto negativo que -sobre la política monetaria y cambiada estaba teniendo la afluencia excesiva de financiamiento extemo de corto plazo, se frenó su velocidad de entrada y se incrementó el costo de ese tipo de financiamiento, al exigirse un encaje no remunerado por el plazo de un año para la mayor parte de los créditos externos y otras fuentes de financiamiento en moneda extranjera, lo que les significó un gravamen cuya carga era función inversa del plazo de dicho financiamiento.

\footnotetext{
${ }^{8}$ Esquema de conversión de deuda externa en inversiones, originado en la crisis de comienzos de los años ochenta.
} 


\section{c) Elevado ahorro interno}

Otra característica significativa de la economía chilena a comienzos de los años noventa fue el elevado nivel que alcanzó el ahorro interno. En efecto, mientras que en el primer quinquenio de los años ochenta el ahorro interno fue inferior al 10\% del PIB, en el segundo quinquenio superó el $16 \%$ y en 1989 fue levemente inferior al 24\% del PIB. Entre 1992 y 1996 la cifra sobrepasó el 25\%. Cabe señalar que el volumen de ahorro interno depende de la actitud del país y de sus políticas frente al ahorro externo, ya que existe abundante evidencia empírica respecto de la sustitución de ahorro interno por ahorro externo, situación que generalmente se produce cuando, en determinadas circunstancias, se acepta indiscriminadamente una entrada "excesiva" de financiamiento externo, en particular de corto plazo.

\section{d) Desarrollo del mercado de capitales}

El desarrollo del mercado de capitales de Chile ha sido muy importante, lo que ha permitido una creciente profundización financiera. En particular, la demanda de documentos emitidos por el Banco Central, tanto por parte de los bancos como de las administradoras de fondos de pensiones y de las compañías de seguros, ha contribuido no sólo a crear un mercado de capitales de largo plazo sino que, además, a la fluida ejecución de operaciones de mercado abierto, las que se han constituido en un eficaz instrumento de la política monetaria.

\section{e) Superávit fiscal}

El presupuesto fiscal fue siempre superavitario, lo que permitió reducir, en términos relativos, la deuda fiscal externa e interna. Pero lo más destacable es que dicho superávit era imprescindible si se deseaba compensar el importante déficit cuasifiscal radicado en el Banco Central; este último se explica, de un lado, por el efecto del "salvataje" del sistema financiero privado chileno efectuado a comienzos de los años ochenta, y, del otro, por las pérdidas del Banco Central como consecuencia de la significativa acumulación de reservas internacionales en la primera mitad de los años noventa.

\section{f) PIB efectivo muy similar al PIB potencial}

Cabe recordar que en el quinquenio 1985-1989 la restricción macroeconómica dominante fue la escasez de divisas, derivada principalmente de la excesiva apreciación del peso de fines de los años setenta y comienzos de los ochenta, y la consiguiente crisis de balanza de pagos y de deuda externa y sus secuelas. Además, el alto crecimiento medio anual del PIB en ese período, de $6.6 \%$, se explicó en medida importante por una recuperación de la fuerte caída que registró en 1982 y 1983 ( $14.1 \%$ y $0.7 \%$, respectivamente), lo que significó que en ese quinquenio la trayectoria del PIB efectivo siguiera muy por debajo a la del producto potencial (salvo en 1989).

En el período 1992-1996, en cambio, casi no hubo holguras en términos de capacidad productiva ociosa ni en el mercado laboral, mientras que la restricción externa desapareció como consecuencia del fuerte crecimiento de las exportaciones y de la gran afluencia de inversión externa directa y de crédito internacional durante esos años. Además, dados el sobrecalentamiento de la economía en 1989 y la evolución posterior del gasto, el crecimiento del PIB en los años noventa se dio en torno al límite de la frontera de producción, o, puesto en otros términos, en condiciones en que el nivel del PIB observado era muy similar al nivel del PIB potencial.

En cuanto a la coyuntura económica a fines de 1989, ésta se caracterizaba por un quinquenio previo que, como se señaló, registró un fuerte crecimiento de la actividad, liderado por el incremento de la formación bruta de capital fijo y de las exportaciones. En ese contexto, con un incremento del PIB de $9.9 \%$ en 1989 , era evidente la presencia de exceso de gasto, reflejado no sólo en un crecimiento económico insostenible en el tiempo, sino además en una aceleración de la inflación y en un excesivo crecimiento de las importaciones. Tal situación requirió de un proceso de ajuste en 1990, caracterizado por la ejecución de una política fiscal austera y una política monetaria restrictiva.

\section{g) Indexation generalizada de los precios}

La indexación generalizada de los precios de la economía es otra característica de la economía chilena. Como consecuencia del crónico proceso inflacionario y de la magnitud y las fluctuaciones inesperadas del crecimiento de los precios, la sociedad chilena se acostumbró a "vivir con la inflación", protegiéndose de parte de sus efectos nocivos mediante la incorporación de cláusulas de reajustabilidad de precios con base en la inflación pasada. Por esa vía, precios tan determinantes como el tipo de cambio, la tasa de interés, los salarios, los arriendos, así como los impuestos, entre otros, han incorporado en buena medida cláusulas de indexación; estas últimas, si bien han aliviado algunos de los problemas derivados de la inflación y han contribuido a elevar el ahorro financiero, también 
han afectado el diseño y la ejecución de las políticas fiscal, monetaria, cambiaría y de remuneraciones.

\section{h) Cuasi inexistencia de deuda fiscal interna}

La deuda fiscal interna en Chile es prácticamente inexistente; ocupa su lugar la deuda interna del Banco Central. En efecto, como consecuencia del rescate de buena parte de la banca privada afectada por la crisis financiera de comienzos de los años ochenta, el Banco Central asumió directa e indirectamente la responsabilidad de evitar los efectos de la monetización de dicha operación de salvataje, emitiendo deuda interna, la mayor parte en pesos "reajustables". Asimismo, durante los años noventa el Banco Central asumió la responsabilidad y el costo de evitar el impacto monetario de la significativa acumulación de reservas internacionales, y lo hizo emitiendo su propia deuda, con lo que en la práctica ha sido el responsable no sólo de la política monetaria sino también de la de Tesorería, es decir, del manejo de la deuda pública interna.

\section{i) Autonomía del Banco Central}

Otra característica que cabe destacar es la recién estrenada autonomía e independencia del Banco Central, determinante en el diseño de la política macroeconómica así como en la voluntad y credibilidad antiinfiacionaria del instituto emisor, con el consiguiente impacto sobre la política fiscal y la formación de expectativas de los distintos agentes económicos.

\section{j) Coincidencia de objetivos entre el gobierno y el Banco Central}

Por último, también tiene importancia la coincidencia de objetivos entre el gobierno y el Banco Central. En efecto, y más allá de diferencias de opinión y de énfasis entre ambos, hubo coordinación y colaboración entre la autoridad fiscal y la monetaria en las líneas gruesas de la política macroeconómica, lo que ciertamente contribuyó a la eficacia en el diseño, la formulación y el resultado de esta política.

\section{IV}

\section{Los criterios para la formulación y ejecución de la política macroeconómica}

Considerando las condiciones iniciales de carácter estructural, institucional y coyuntural que caracterizaban a la economía chilena a fines de los años ochenta, el Banco Central fijó cuatro criterios básicos que marcarían su accionar durante el primer quinquenio de los años noventa.

\section{El equilibrio macroeconómico global}

Un criterio fundamental de la política antiinflacionaria del Banco Central fue no generar desequilibrios importantes en otras áreas claves de la economía. En efecto, los logros en materia de inflación no debían darse a costa de generar un incremento sustancial en los niveles de desempleo y capacidad ociosa, desajustes en los mercados financieros o un deterioro no sostenible en las cuentas externas. Estos desequilibrios, internos o externos, no sólo tienen costos elevados por sí mismos, sino que además erosionan la credibilidad del esfuerzo de estabilización, ponen en duda su sustentabilidad, retardan sus efectos y al final resultan contraproducentes, si es que dicho esfuerzo termina por ser abandonado a medio camino.

\section{Horizontes de mediano y largo plazo}

Un segundo criterio fundamental para entender el accionar del Banco Central de Chile en el primer quinquenio de los años noventa, fue el horizonte temporal que éste tuvo en consideración al adoptar sus políticas. Siempre se procuró que sus decisiones privilegiaran la estabilidad y solidez de la economía, lo que significó plantearse un horizonte temporal que tomara en consideración, principalmente, las tendencias de mediano y largo plazo; es decir, las políticas del Banco debían trascender la coyuntura diaria.

La coyuntura económica ciertamente debe ser observada con atención, ya que influye sobre la trayectoria futura de las distintas variables económicas. No obstante, la perspectiva en función de la cual el Banco Central debe tomar sus decisiones es la de mediano y largo plazo. Ello, por cuanto lo que interesa en definitiva es asegurar la estabilidad de las principales variables macroeconómicas a lo largo del tiempo, y no generar auges transitorios o pasajeros que después deban ser revertidos, con el consiguiente impacto ne- 
gativo en términos de ampliar los ciclos de actividad y contracción, así como por el efecto que tendría la mayor incertidumbre en la toma de decisiones de los agentes económicos.

La importancia del horizonte de mediano y largo plazo en las decisiones del Banco Central tiene diversos fundamentos. De un lado, existe una permanente discusión en torno a los efectos de mediano y largo plazo de medidas cortoplacistas. En efecto, en ciertas circunstancias es posible estimular el crecimiento económico, transitoriamente, con una política monetaria más relajada. Sin embargo, ésta reflejaría una visión de corto plazo, ya que por lo general dañaría las posibilidades de crecimiento de largo plazo del país. Además, con toda seguridad más temprano que tarde será necesario aplicar una política de ajuste, y, por consiguiente, volver a una política monetaria más restrictiva. Es por este conflicto entre el corto y el largo plazo que muchos países han decidido dar autonomía a sus bancos centrales, dejándoles como objetivo básico la lucha contra la inflación. De esta manera, la política monetaria pasa a tener un horizonte de tiempo mayor debido, precisamente, a la necesidad de evitar que se imponga una visión de corto plazo en su ejecución; esto último, de darse, tiende a manifestarse en la adopción de decisiones apresuradas, cuando no abiertamente equivocadas de política monetaria, cada vez que algunos indicadores económicos muestran cierta debilidad.

En segundo lugar, al Banco Central de Chile se le criticó en varias ocasiones, quizás por no estarse al tanto de la vigencia del criterio de mediano y largo plazo en su accionar, por no haber conseguido avances de importancia en la estabilidad de precios. Se argumentaba que habría sido posible avanzar con más rapidez en esta materia y a menudo se citaban las experiencias de otros países de la región, que aparecían logrando resultados más rápidos o espectaculares que los de Chile en el control de la inflación. Frente a dicha crítica cabe señalar que sí hubo avances notables en el control y reducción de la inflación. En efecto, después de alcanzar $27.3 \%$ en 1990 , el ritmo de crecimiento de los precios cayó sistemáticamente, a valores casi idénticos a los de las metas programadas de inflación. En 1996 la inflación fue de 6.6\%, muy similar a la meta establecida de $6.5 \%$ a fines de año. Por otro lado, la indexación, aunque tiene aspectos positivos, hace demasiado costosa-en términos de producto y empleo- la reducción abrupta de la inflación. Por ello es que se prefirió atacar la inflación con una estrategia gradual, sobre una base consistente y segura. Cabe también destacar que en Chile no se utilizó el tipo de cambio con fines antiinflacionarios. Por cierto, si se lo hubiera utilizado se habría avanzado más rápidamente en la reducción de la inflación, pero lo más probable es que los beneficios de corto plazo de esa estrategia se hubiesen visto contrarrestados por los costos que se producirían en plazos más largos. La dolorosa experiencia de principios de los años ochenta era algo que el Banco Central de Chile no estaba dispuesto a repetir. Tal como quedó demostrado en esa oportunidad, la utilización del tipo de cambio para lograr mejores resultados antiinflacionarios es una política que la mayor parte de las veces tiende a volcarse en algún momento en contra de la consecución del objetivo buscado. ${ }^{9}$

En tercer lugar, la experiencia ha demostrado que la política monetaria opera con rezagos sobre el curso de la economía: para un país como Chile, las medidas en este campo deben adoptarse teniendo en cuenta sus efectos en los siguientes seis a dieciocho meses.

Finalmente, en diversas ocasiones entran en contradicción las conductas de agentes cuyos horizontes son de muy corto plazo, con los elementos que definen las condiciones de equilibrio y desarrollo de mediano y largo plazo. Por ejemplo, la lógica financiera, que las más de las veces es de cortísimo plazo, puede entregar señales y determinar precios que induzcan al sector transable de la economía a adoptar erróneas decisiones de inversión y de asignación de recursos. Asimismo, horizontes temporales cortos, típicos de algunos medios de opinión o de sectores específicos de actividad, pueden afectar las expectativas y las decisiones de inversión e incluso las opciones de política de la autoridad, mediante señales y precios incorrectos desde una perspectiva de desarrollo de mediano y largo plazo. Así, nuevamente se justifica la visión de mediano y largo plazo del Banco Central, la que contribuye a corregir o al menos a limitar el efecto distorsionador de un excesivo cortoplacismo en las conductas de los agentes económicos,

\section{Prudencia y gradualidad}

El Banco Central es una institución que por la propia definición de sus objetivos — velar por la estabilidad de la moneda y por el normal funcionamiento de los pa-

\footnotetext{
${ }^{9}$ En efecto, tarde o temprano la apreciación de la moneda se hace insostenible, se generan efectos laterales, costosos y complejos, en otras áreas claves de la economía, como la pérdida de competitividad y el deterioro del sistema bancario, y/o se termina en una devaluación, lo que anula completamente los avances antiinflacionarios.
} 
gos internos y externos- debe ser muy prudente. Cualquier decisión tomada en forma apresurada y sin una evaluación previa de sus efectos puede y suele tener consecuencias muy dañinas para la marcha de la economía.

Por su parte, el criterio de operar sobre horizontes de mediano plazo también sugiere reaccionar con prudencia frente a las variaciones coyunturales que presentan indicadores aislados. Las decisiones de política monetaria y cambiaría deben basarse en la tendencia de un conjunto amplio de indicadores, y no en datos puntuales de uno o dos meses. En términos concretos, las medidas de política que adoptó el Banco Central de Chile no surgieron de reacciones apresuradas ante los indicadores de un mes o de un período en particular o ante cifras aisladas, por muy espectaculares que éstas fueran. Al respecto, es importante aclarar que las fluctuaciones mensuales que presentan por ejemplo el índice Mensual de Actividad Económica (IMACEC) o el propio índice de Precios al Consumidor (IPC), constituyen sólo un par de antecedentes más, y adquieren su verdadera relevancia cuando se les utiliza no en forma aislada, sino en términos de su tendencia y en conjunto con otros indicadores complementarios, como el curso del empleo, de los salarios, del tipo de cambio, del gasto, y de la balanza comercial y de pagos. $^{10}$

Conforme a este criterio, el Banco Central debe avanzar sobre bases sólidas, lo que no significa reaccionar tardíamente. Por el contrario, lo que es de gran importancia, el instituto emisor siempre intentó tomar medidas anticipándose a la inflación y no esperando a que ésta se manifestara abiertamente. En efecto, como la inflación se presenta con rezagos, el Banco Central debe estar atento a los signos incipientes de presiones inflacionarias y actuar con firmeza para prevenirlas y neutralizarlas lo más pronto posible. Así, no es prudente y sería ineficiente postergar ciertos ajustes en espera de que los desequilibrios se vean reflejados en la propia tasa de inflación. A esas alturas la inercia que se introduce a través de los reajustes nominales de salarios y precios, unida a la pérdida de credibilidad sobre el compromiso antiinflacionario de las autoridades, hacen que se necesite una dosis de ajuste más fuerte para lograr los mismos resultados sobre la inflación,

\footnotetext{
${ }^{10}$ Cabe destacar, asimismo, que este criterio de prudencia y gradualidad no sólo es útil para entender la política monetaria y cambiaría del Banco Central de Chile durante los años noventa, sino también para comprender su estrategia en relación con la apertura de la cuenta de capitales.
}

pero con costos bastante más elevados en términos de empleo y actividad económica.

En consecuencia, las reacciones de la autoridad monetaria deben ser oportunas, pero nunca apresuradas. En ocasiones se criticó al instituto emisor por no reaccionar de inmediato frente a determinadas señales del mercado. La verdad es que la mayoría de las veces habría sido un error del Banco Central reaccionar ante un fenómeno coyuntura!, que tiene alta probabilidad de revertirse en el futuro. Una conducta de esa naturaleza sólo induciría a tener que adoptar, en breve lapso, decisiones en un sentido y luego en otro contrario, con lo cual sólo se terminaría agregando más "ruido" a la economía y generando efectos adversos sobre el nivel de actividad, la inversión y el empleo.

De otro lado, la experiencia histórica chilena, así como la de varios países latinoamericanos, indica que las medidas muy drásticas o de shock se justifican fundamentalmente en presencia de situaciones críticas o de coyunturas muy particulares, como una inflación muy elevada y descontrolada o un déficit fiscal creciente, o para lograr un significativo vuelco en las expectativas. Sin embargo, el impacto de las políticas del Banco Central es tan grande y tiene tantas repercusiones en distintos sectores económicos que como regla general se debe ser muy prudente y avanzar de manera gradual en la adopción de ellas. Por la misma razón es preciso evaluar sistemáticamente cuáles son sus efectos directos y laterales. Es en este sentido que la gradualidad y la prudencia son muy buenos rectores para la toma de decisiones, toda vez que permiten ir corrigiendo situaciones en forma no traumática. Más concretamente, no debiera tener interés el Banco Central en mostrar resultados espectaculares que el menor imponderable pudiera revertir. Por el contrario, parece más adecuado preferir avances más pausados, pero sobre bases estables y sólidas, donde lo que se logre quede firmemente consolidado.

Es importante hacer hincapié en la acepción de gradualidad al describir la política antiinflacionaria, puesto que pudiendo parecer deseables avances más significativos y rápidos en esta materia, ellos pueden llegar a tener un costo demasiado alto en términos de empleo y producción, sobre todo en casos como el chileno, donde las prácticas de indexación (en función de la inflación pasada) son generalizadas y se extienden a las más diversas transacciones. Así, al igual que en otras materias, en el tema antiinflacionario se privilegió una estrategia gradual, pero fundada en bases sólidas y permanentes. Esto permitió que los avances logrados fueran y se percibieran bien cimentados y que 
no debieran revertirse en el futuro. Por lo demás, y puesto que la propia estrategia antiinflacionaria se insertó en el criterio del equilibrio macroeconómico global, la economía chilena no presentó ningún desequilibrio de magnitud que hubiese hecho temer un desborde inflacionario en el futuro previsible. Obsérvese asimismo que una política de reducción de la inflación que sea gradual y sostenida permite que, a medida que el instituto emisor va ganando credibilidad, los contratos y las expectativas incorporen las metas de inflación descendente establecidas por el Banco Central, minimizando los riesgos de generar desequilibrios en otros mercados y consolidando la permanencia en el tiempo de los avances obtenidos.

Cabe destacar que con ese enfoque gradual se logró algo muy significativo: consolidar la inflación en un rango no visto en Chile en décadas. En efecto, en las últimas dos oportunidades en las que el país alcanzó un nivel de inflación similar, aunque algo superior al registrado a mediados de los años noventa, los desequilibrios acumulados fueron tales que en pocos meses todo lo ganado se perdió dramáticamente. Uno de estos episodios se dio en 1981, cuando luego de la fijación del tipo de cambio la inflación llegó a 9.5\%; en esa ocasión el desequilibrio externo fue tal que al año siguiente hubo que devaluar y la inflación aumentó a más de $20 \%$. El otro episodio, más reciente, ocurrió a fines de los años 80, cuando luego de llegar a menos de $13 \%$ en 1988, la inflación volvió a acelerarse en 1989 debido al fuerte incremento del gasto acumulado en los años previos. Lo importante, en consecuencia, es alcanzar una reducción pemianente y sostenida de la inflación, y no reducirla uno o dos años para que luego se reacelere. De hecho, en el período 1992-1996 se alcanzó una tasa de inflación media anual de 9.7\%, que es la menor tasa registrada para un quinquenio desde hace más de medio siglo en Chile, debiendo destacarse que dicho logro antiinflacionario se dio en un entorno de fuerte pero sostenible dinamismo de la actividad económica, y de sólidas cuentas externas.

El criterio de gradualidad, unido al del horizonte de mediano y largo plazo, también se refleja en la estrategia de apertura de la cuenta de capitales. Tal como se analiza más adelante, el Banco Central avanzó significativamente en esta materia en los últimos años. Sin embargo, algunos analistas sostienen que el avance debió haber sido aún más rápido, llegándose incluso a sugerir una apertura financiera total en forma inmediata e indiscriminada. El problema de una apertura apresurada es que suele generar trastornos graves en la economía, entre otros, bruscas alteraciones en el tipo de cambio real o problemas en el sector financiero. Sin ir más lejos, cabe recordar las experiencias de apertura indiscriminada de la cuenta de capitales que se llevaron a cabo en algunos países latinoamericanos a fines de los años setenta, y otras más recientes, previas a la crisis de México de fines de 1994, y que terminaron en su gran mayoría en estruendosos fracasos y con una cuenta de capitales más cerrada en la práctica que al inicio de la experiencia.

Con este argumento se intenta destacar que, siendo deseable una creciente y decidida inserción en los mercados financieros internacionales, el éxito del proceso depende en buena medida de que su modalidad, velocidad y selectividad sean apropiadas para que no se generen mayores trastornos en la economía nacional, razón por la cual la apertura financiera debe ser llevada a cabo en forma prudente, cuidadosa y gradual.

\section{El papel del mercado en la determinación de precios claves}

En la economía existen ciertos precios claves que es fundamental determinar en forma correcta, es decir, de manera que reflejen las verdaderas condiciones de oferta y demanda, que son aquéllas de carácter más estructural. Los principales precios son los salarios, la tasa de interés, el tipo de cambio y los precios de determinados activos, especialmente los bursátiles y del sector inmobiliario. Los dos precios claves en los cuales el Banco Central tiene mayor injerencia son el tipo de cambio y la tasa de interés. Si estos precios están desalineados respecto de sus determinantes fundamentales suele producirse un grave daño para el sistema financiero y para la vigencia de los equilibrios macroeconómicos básicos.

Existen importantes precedentes, especialmente en América Latina, de precios claves distorsionados que se tradujeron posteriormente en grandes crisis. Por lo general, uno de los primeros sectores afectados ha sido el financiero. Así por ejemplo, legislaciones, supervisiones o regulaciones inadecuadas para el sistema financiero han producido lo que se conoce como los problemas de "riesgo moral" y de "agencia", que contribuyen a que prevalezcan tasas de interés anormalmente altas. Dichas tasas de interés, aunque son de mercado, no son de equilibrio ni sostenibles en el tiempo, y terminan por minar la capacidad de pago de los deudores del sistema financiero. Lo sucedido en Chile en la segunda mitad de los años setenta es ilustrativo en esta materia. No son pocos quienes atribuyen la 
crisis financiera de esa época a tasas de interés reales extraordinariamente elevadas, que aun siendo de mercado, no pudieron ser soportadas indefinidamente por el sistema. En casos como éste la política monetaria se loma muy ineficiente, a la vez que la fragilidad del sistema bancario se exacerba, poniendo en peligro los logros macroeconómicos.

Algo similar puede ocurrir con el otro precio clave anteriormente mencionado: el tipo de cambio. La fijación de un tipo de cambio excesivamente depreciado, o una apertura indiscriminada o muy rápida de la cuenta de capitales, suele traducirse en un fuerte endeudamiento externo, por lo general de corto plazo, y en una moneda interna excesivamente apreciada. Cuando la situación debe revertirse - para hacer frente al servicio de dicha deuda- los efectos suelen ser traumáticos: hay fuertes caídas de los salarios reales y del empleo y/o se afecta la liquidez y solvencia del sistema financiero, todo lo cual pone en jaque los equilibrios macroeconómicos. De otro lado, los efectos sobre la cuenta corriente de la balanza de pagos de una moneda interna excesivamente apreciada tornan al país muy vulnerable a cualquier perturbación externa negativa o a cambios en las expectativas de los acreedores e inversionistas internacionales.

En síntesis, los precios claves distorsionados pueden producir graves crisis tanto en el sistema financiero como en la mantención de los equilibrios macroeconómicos.
Esto no significa que las autoridades deban intervenir constantemente en estos mercados. Más bien debiera ocurrir lo contrario, es decir, disminuir la intervención oficial al mínimo posible, o sólo cuando se está produciendo un desequilibrio de corto plazo importante, y establecer los mecanismos que permitan ejercer una regulación y supervisión adecuadas al amparo de las cuales el mercado se desenvuelva más libre y eficientemente.

Teniendo presente lo anterior, cabe destacar que uno de los objetivos explícitos del Banco Central fue dar un papel cada vez mayor al mercado en la determinación de estos precios macroeconómicos claves. Esto, por cuanto a medida que los mercados financiero y cambiario chilenos se desarrollan, profundizan y se hacen más sofisticados, menores son las fallas del mercado en la determinación de dichos precios. Aquí se inscriben, por ejemplo, la ampliación de la banda de fluctuación del tipo de cambio, la flexibilización de las operaciones cambiarías que pueden realizar los bancos y el desarrollo de mecanismos privados para cubrirse de riesgos cambiarlos; y en el ámbito monetario-financiero, la creciente modalidad de licitación de pagarés del Banco Central, de modo que en la actualidad el Banco Central concentra el grueso de su política monetaria en el manejo directo de la tasa de interés a un día, mientras que el mercado es un actor cada vez más preponderante en la determinación de tasas de interés para plazos mayores.

\section{V}

\section{Las políticas del Banco Central ${ }^{11}$}

\section{La política monetaria}

La política monetaria del Banco Central de Chile se basó en el control de las tasas de interés reales' ${ }^{2}$ de

\footnotetext{
${ }^{1}$ El control de la demanda agregada, que es el fundamento central de la estabilidad macroeconómica, necesita de la coordinación entre la política fiscal y la política monetaria. Más aún, esa coordinación debe ir más allá de no monetizar los déficit públicos, debiendo abarcar también el control del crecimiento del gasto público en el mediano plazo y el diseño de una política fiscal y tributaria explícitamente contracíclica. Sin embargo, el tratamiento de los aspectos de coordinación de ambos ámbitos de política y los detalles de la política fiscal del período excede los alcances del presente artículo. Su omisión del mismo es un reconocimiento de su importancia, pues obligaría a un tratamiento equivalente al que se da a las políticas del Banco Central,
}

corto plazo en un nivel coherente con la meta de inflación. El fundamento de esta política radica en la influencia de las tasas de interés sobre el ritmo de expansión del gasto agregado.

Para alcanzar un objetivo nominal como la estabilidad de precios se requiere que la política monetaria disponga de algún "ancla" nominal. Dos de las anclas más utilizadas son el control de algún agregado monetario y el uso del tipo de cambio nominal. En el caso chileno se descartó la primera por no encontrarse un vínculo estable y predecible entre agregados mo-

\footnotetext{
12 Debido a la indexation de la economía chilena, se utilizó una tasa de interés real, es decir, ajustada por la tasa de inflación,
} 
netarios nominales y el gasto o el ingreso nominal, debido principalmente a la inestabilidad de la demanda de dinero de corto plazo. En esas circunstancias, establecer metas intermedias fijas sería ineficiente para alcanzar un determinado objetivo y, además, generaría grandes fluctuaciones de la tasa de interés, lo que afectaría a la inversión y a la actividad económica. El uso del tipo de cambio nominal como ancla monetaria ha demostrado ser, en distintas experiencias internacionales, un instrumento muy riesgoso, que suele acarrear grandes costos en términos de empleo y pérdida de competitividad externa. Por lo general, los logros antiinflacionarios conseguidos con este instrumento son transitorios, como se vio en Chile a comienzos de los años ochenta; en efecto, la excesiva apreciación de la moneda local perjudica el logro del equilibrio externo, generándose una devaluación que termina anulando, cuando no revirtiendo, los avances logrados en la reducción de la inflación. Además, un ancla de esta naturaleza impone una excesiva rigidez en el diseño y la formulación de la política económica general.

La inestabilidad en la relación entre estos objetivos intermedios y el objetivo final de la inflación controlada llevó al Banco Central a centrar su acción directamente en el objetivo final: la meta de inflación. En efecto, el ancla nominal de la política monetaria fue la meta explícita de inflación, anunciada anualmente en la presentación del Banco Central ante el Senado. La trayectoria anual de la meta de inflación fue decreciente, y su valor se fijó de común acuerdo con el Ministerio de Hacienda, en función de avanzar hacia la estabilidad de precios, pero sin sacrificar la actividad económica, el empleo u otras variables macroeconómicas claves, como el ahorro y la inversión, el equilibrio externo o la estabilidad y solvencia del sistema financiero. ${ }^{13}$

El rol de la meta de inflación como hilo conductor de la política le permitió al Banco Central desarrollar una acción preventiva y oportuna, basada en toda la información disponible, que se calibraba directamente en función de la evolución misma de la inflación subyacente o de tendencia, La contrapartida de la flexibilidad otorgada por la estrategia que tiene un objetivo final de inflación, sin objetivos intermedios de políti-

\footnotetext{
${ }^{13}$ Dicha política obliga a la autoridad monetaria, cuando enfrenta una perturbación inesperada o cuando la inflación efectiva se desvía significativamente de la niela, a efectuar cuando la oportunidad lo requiera y con la fuerza necesaria, las modificaciones que se precisen para enfrentar esas situaciones y poder cumplir con la meta de inflación.
}

ca monetaria, es que ella requiere de gran credibilidad. Cabe destacar que si bien el Banco Central no estableció objetivos intermedios explícitos, siempre se mantuvo vigilante ante los primeros indicios de desequilibrios macroeconómicos; en particular, de las desviaciones de los niveles y de la tasa de crecimiento entre el gasto interno y el PIB efectivo, de un lado, y entre el PIB efectivo y el potencial, del otro.

La brecha entre el crecimiento del gasto interno y el crecimiento del PIB es una señal de la evolución futura de las cuentas externas del país. Si el crecimiento del gasto es más rápido, indica una acentuación del déficit en la cuenta corriente de la balanza de pagos. Dependiendo del punto de partida inicial, de la evolución de los términos del intercambio y del objetivo de equilibrio externo, dicho deterioro puede no ser motivo de mayor preocupación. Sin embargo una discrepancia significativa y duradera es más que una señal de alerta respecto al incumplimiento del objetivo de equilibrio externo y a la necesidad de realizar un ajuste.

Por su lado, la brecha entre el PIB efectivo y el potencial anticipa quiebres en el componente interno de la tendencia inflacionaria, aun cuando el rezago y la magnitud de dicha relación sea variable. Naturalmente, para determinar esta brecha es preciso disponer de alguna forma de estimación del PIB potencial. ${ }^{14}$

Tampoco es posible ignorar la contribución asociada a la existencia de determinadas condiciones que aseguran el funcionamiento apropiado de una economía de mercado y que tienen un efecto positivo en la productividad. $^{15}$

No obstante, no debe perderse de vista que la brecha del producto, es decir, la diferencia entre el PIB efectivo y el PIB potencial, es sólo uno de los factores determinantes de la inflación. En todo caso, aquí cabe distinguir entre tasas de crecimiento y niveles del producto. La inflación depende, principalmente, de los niveles del producto, o en otros términos, es la diferencia entre el PIB efectivo y el PIB potencial la que

\footnotetext{
${ }^{14}$ Para ello se estima una función de producción, en la cual el acervo físico de capital es sin duda un elemento importante y que viene a reflejar la existencia de una estrecha correlación entre el crecimiento económico y el nivel de la tasa de inversión. Esto no significa postular una relación lineal simple entre crecimiento e inversión, ni desconocer que hay otros elementos en aquella función, como la tecnología, la fuerza laboral y su calificación.

${ }^{15}$ En efecto, como es bien sabido, la existencia de precios que reflejen adecuadamente las condiciones de escasez relativa, la competencia, la apertura de la economía, etc,, son, entre otros, importantes factores que permiten elevar los niveles de productividad y, en consecuencia, el nivel $-\mathrm{y}$ probablemente también ¡a tasa de crecimiento- del PIB potencial.
} 
ejerce presión sobre los precios. Esto no deja de tener importancia, por cuanto si un país se encuentra, en un determinado momento, con un nivel de producto que está significativamente por debajo de su potencial, es posible que crezca a tasas superiores a las de crecimiento del producto potencial, disminuyendo así la brecha del producto, sin que esto se traduzca en mayores problemas inflacionarios. ${ }^{16}$

En cuanto a la implementación de la política monetaria, la brecha del producto fue uno de varios indicadores, aunque no por ello de menor significación. En efecto, hay otros indicadores que también deben ser ponderados al momento de tomar una decisión sobre política monetaria. En el caso de Chile se utilizaron, entre otros, indicadores del mercado laboral (incremento nominal y real de salarios, estrechez del mercado, etc); evolución de los agregados monetarios (tasas de crecimiento de M1, M2, etc); información de créditos (tasas de crecimiento de los préstamos de consumo, de los créditos hipotecarios, del crédito total del sector privado, etc); indicadores del gasto agregado (ventas industriales, importaciones, consumo privado); trayectoria de la inflación y de algunos precios (tipo de cambio, precios del sector no transable, etc). De esta manera, si por ejemplo el país se viera afectado por un fenómeno recesivo, pero al mismo tiempo las demandas salariales siguieran subiendo, la política monetaria no debería relajarse hasta que tales presiones de costo hubiesen desaparecido. Lo mismo sería válido si otros indicadores, como los recién mencionados, no estuvieran en línea con los objetivos del Banco Central en materia de estabilidad de precios. En síntesis, lo que se quiere destacar es que la brecha del producto no es el tínico determinante de la inflación.

Un problema con el enfoque recién reseñado surge cuando hay señales mixtas. Teóricamente, un aumento de la brecha del producto debería ir acompañado de otros elementos que mostraran, también, una caída en las presiones inflacionarias. Esto se debe a que un crecimiento económico bajo reduce el ritmo de crecimiento de la demanda tanto de dinero como de crédito. De igual modo, como la demanda en el mercado laboral disminuye, debieran decrecer también las presiones salariales. Esto es lo que en teoría cabría esperar: tener señales claras tanto para el corto como para el largo plazo. Sin embargo, en la práctica la po-

\footnotetext{
${ }^{16}$ Este es uno de los factores que explica lo ocurrido en Chile durante la segunda mitad de los años ochenta, en que el punto de partida del PIB fue muy bajo debido a la profunda recesión de comienzos de dicha década.
}

lítica monetaria es bastante más compleja y no se puede esperar el largo plazo para tener señales que no sean ambiguas. Más aún, la existencia de señales mixtas es la regla y no la excepción. Por ejemplo, la recuperación de una economía puede ser un hecho de relativa inminencia pero distar aún de reflejarse en el producto o en otras mediciones de la actividad económica. En ese caso, si la autoridad monetaria sobrerreacciona a la brecha del producto, podría estar incubando o potenciando problemas de inflación en el futuro. Con esto se quiere subrayar que si bien la brecha del producto es un indicador importante, no debe asignársele una ponderación desmedida y menos aún considerársele como el objetivo final de la política monetaria. Nuevamente lo que está en juego aquí es la credibilidad del Banco Central. Para mantenerla, es imperioso que éste muestre un fuerte compromiso con su meta principal: la estabilidad de precios.

De otro lado, cabe formular algunas precisiones sobre el bien conocido tema del sentido de oportunidad (timing) en política monetaria. Se han señalado ya algunas de las razones de por qué asignar una ponderación desproporcionada a la brecha del producto puede resultar inadecuado en términos del objetivo de la estabilidad de precios. Otra razón para ello está relacionada con la habilidad para escoger el momento oportuno. La información sobre la evolución de la actividad económica tiene rezagos significativos y se conocen las limitaciones de que adolecen los principales indicadores. Además, existen rezagos entre el momento en que se aplican medidas de política monetaria y el momento en que ellas generan efectos. Por lo tanto, las autoridades monetarias siempre enfrentan el riesgo de sobrerreaccionar —en una recesión, por ejemplo- si no ven antecedentes que muestren una recuperación. En estos casos la prudencia aconseja emplear otros indicadores para confirmar o desmentir una eventual reactivación. La impaciencia en este sentido, reflejada en un estímulo monetario adicional por parte del Banco Central, podría desembocar finalmente en mayores presiones inflacionarias. Lo contrario ocurriría en épocas de auge: si la desaceleración ya ha sido inducida, una mayor restricción monetaria la agudizaría. En resumen, es fundamental que la política monetaria intente ser anticipatoria y preventiva y que las autoridades monetarias tengan siempre presente la existencia de rezagos y que una acción tardía puede terminar ampliando el ciclo económico en lugar de suavizarlo.

En cuanto a la ejecución de la política monetaria, a mediados de 1995 se modificó la forma en que ésta había operado por más de una década. En efecto, con 
miras a utilizar instrumentos más flexibles y eficientes, el Banco Central dejó de fijar directamente la tasa de interés de los documentos del Banco Central a 90 días y concentró la política en la tasa de interés a un día. ${ }^{17}$ Los propósitos de estas medidas fueron, de un lado, otorgar una mayor participación al mercado en la determinación del precio de todos los documentos emitidos por el Banco Central, y no sólo de la tasa de interés de los documentos de mediano y largo plazo; de otro, regular en mejor forma la liquidez y evitar que las expectativas en torno a posibles cambios en la tasa de interés de documentos a mayor plazo del Banco Central distorsionaran las operaciones del mercado interbancario. De hecho, la utilización de la tasa de interés a un día como principal instrumento monetario ha sido probada como una manera eficaz de minimizar la influencia de las expectativas de ganancias o pérdidas de capital y como una herramienta eficiente en los países con mercados financieros más desarrollados. Por lo demás, la medida era coherente con la creciente integración financiera de la economía chilena, permitiendo una forma más flexible de hacer política monetaria. En efecto, por la interrelación de las tasas de interés internas y externas es aconsejable eliminar rigideces que incentiven movimientos indeseados de recursos financieros y que impidan que los ajustes puedan realizarse de manera más compartida entre el tipo de cambio y las tasas de interés, lo que significa un manejo menos complicado y más eficiente de la política monetaria.

En síntesis, la nueva modalidad de política monetaria es más eficaz, permitiéndole al Banco Central mayor iniciativa, flexibilidad y frecuencia de los movimientos de las tasas de interés cortas, las que a su vez afectan al resto de las tasas, que son determinadas cada vez más por el mercado; lo anterior permite un mayor control de las condiciones de liquidez para influir sobre el curso del gasto agregado y de la inflación. En esas condiciones, el impacto y la volatilidad derivada de las perturbaciones que afectan a la economía chilena se distribuyen equilibradamente entre movimientos del tipo de cambio, de las tasas de interés y de las reservas internacionales, y la recomposición de cartera.

\footnotetext{
${ }^{17}$ Como complemento de la política de tasas, el Banco Central llevó a cabo un importante cambio en ¡a determinación de las condiciones de liquidez de la economía, permitiendo que el mercado desempéñala un papel cada vez mayor en la determinación de las lasas de interés de mediano y largo plazo y alargando el período de madurez de la deuda pública interna.
}

\section{La política cambiaría}

Luego de haberse renovado el acceso al financiamiento externo voluntario en los años noventa, la experiencia de comienzos del decenio anterior previno a la autoridad económica en contra de basar la lucha antiinflacionaria en un solo instrumento, como el tipo de cambio. Dicha práctica puede conducir a graves desequilibrios macroeconómicos y por lo tanto al fracaso. Asimismo, se ha visto que el intento de forzar el valor del tipo de cambio real a un nivel alto también está destinado al fracaso si la política cambiaría no va acompañada de políticas macroeconómicas extremadamente austeras, lo que puede llevar a sacrificar capacidad de crecimiento futuro, por el impacto adverso que dicho contexto suele tener sobre la inversión. ${ }^{18}$ Por lo mismo, un tipo de cambio real artificialmente alto también carece de sentido, excepto en coyunturas críticas. En consecuencia, la política cambiaría del primer quinquenio de los años noventa intentó evitar desviaciones importantes que pudieran alejar el tipo de cambio de mercado de su trayectoria de equilibrio de mediano y largo plazo. ${ }^{19}$

En el primer quinquenio de los años noventa la economía chilena se encontraba en una fase de desarrollo distinta de la que existió en décadas anteriores. Su reinserción estructural en la economía internacional se hacía cada vez más evidente, tanto en lo financiero como en materia de comercio real. El sector exportador se iba diversificando y ampliaba de manera importante su cobertura de productos y de mercados. La economía estaba mucho más abierta y los aranceles

\footnotetext{
${ }^{18}$ Con posterioridad a la crisis de 1982 , Chile enfrentó una fuerte restricción externa provocada principalmente por el cese de la entrada de capitales voluntarios. Ello hizo indispensable un tipo de cambio real suficientemente alto que, mediante el estímulo a las exportaciones y actividades sustitutivas de importaciones, permitiera generar las divisas requeridas. Las políticas fiscal y monetaria de la época se orientaron fundamentalmente a lograr un tipo de cambio real "alto", lo que se logró en buena medida debido al elevado desempleo, que hizo posible una baja en los salarios reales. De otro lado, si bien el gasto se mantuvo en un nivel moderado para evitar la espiral inflacionaria que podían provocar las devaluaciones, no se logró avanzar en materia antiinflacionaria.

${ }^{19}$ No puede pretenderse que el Banco Central fije el tipo de cambio real en una economía como la chilena de los años noventa. En efecto, el creciente proceso de integración comercial y financiera, la volatilidad de los términos del intercambio, los cambios en la clasificación del riesgo-país, la inversión en el sector productor de bienes transables y el desigual desarrollo tecnológico de los sectores de bienes transables y no transables llevan a que el tipo de cambio real de equilibrio varíe. Esto significa que a medida que se van generando estos cambios estructurales, se modifica el tipo de cambio real que asegura el equilibrio externo, y el Banco Central debe permitir el necesario ajuste.
} 
continuaban bajando. La inversión extranjera hacia y desde Chile se incrementaba a niveles muy elevados. Además, todos los indicadores de solvencia externa mejoraban notablemente, a la vez que el riesgo-país y la vulnerabilidad externa disminuían en forma significativa. Así, en ese nuevo entorno, la política cambiaría también se adaptó.

En efecto, durante el primer quinquenio de los años noventa la formulación y ejecución de la política cambiaría tuvo como objetivo principal complementar a las políticas fiscal y monetaria para el logro del equilibrio externo de la economía en el mediano plazo. Para ese fin se procuró dar lugar a un flujo de ahorro externo que complementaría las fuentes internas en el financiamiento de la inversión, lo que significó buscar un déficit de cuenta corriente de la balanza de pagos de 3 a 4\% del PIB, de carácter estructural o de tendencia, como una manera de materializar el objetivo legal del normal funcionamiento de los pagos externos. ${ }^{20} \mathrm{La}$ razón para sostener dicho rango radica en que un ahorro externo menor no es adecuado para un país como Chile: éste requiere una contribución externa a su ahorro interno para financiar una alta tasa de inversión y, de otro lado, la ocurrencia en la cuenta corriente de la balanza de pagos de déficit permanentemente superiores a ese rango podría poner en peligro la solvencia de la economía chilena. En síntesis, se deseaba evitar un endeudamiento externo a niveles tales que pudiese aumentar la vulnerabilidad de la economía nacional frente a perturbaciones inesperadas. ${ }^{2,}$

\footnotetext{
${ }^{20}$ Por supuesto que el rango mencionado, de 3 a $4 \%$ del PIB, no debe tomarse en forma rígida. De hecho, en algunos años pueden producirse situaciones transitorias que lleven a un nivel superior o inferior al indicado. Por ejemplo, en 1992 y 1994 el déficit en cuenta corriente de la balanza de pagos fue muy inferior al rango mencionado, e incluso hubo un pequeño superávit en 1991 y 1995. Por otro lado, en 1993 y 1996 la perturbación que afectó al precio de los principales productos de exportación fue de tal magnitud que el déficit en cuenta corriente superó levemente la cota máxima de $4 \%$. En consecuencia, lo importante no es el resultado de un año en particular, sino la tendencia que se observe en esta materia. En tal contexto, cabe reiterar que el tipo de cambio real de equilibrio es aquel que genera en el mediano y largo plazo los objetivos planteados para la cuenta corriente. Aquí está presente de nuevo el criterio de mediano y largo plazo, tan recurrente en la estrategia del Banco Central de Chile durante la primera mitad de los años noventa.

${ }^{21}$ Dicha vulnerabilidad ha sido disminuida en forma notable. Por ejemplo, en 1993, a pesar de ser un año muy negativo en términos del precio de las exportaciones chilenas, la economía creció más de $6 \%$ sin que se generaran presiones inflacionarias ni de devaluación. Cabe destacar que históricamente la economía chilena estaba acostumbrada a sufrir severas recesiones, acompañadas de devaluaciones c incrementos en la inflación, cada vez que había una perturbación extema de cierta magnitud.
}

Un segundo objetivo de la política cambiaría fue enfrentar las fluctuaciones transitorias de corto plazo del tipo de cambio para neutralizar en parte el efecto de la afluencia de capitales especulativos, que pueden dañar tanto el logro del equilibrio interno como del externo.

Simultáneamente, la política seguida permitió llevar adelante gradualmente el proceso de fortalecimiento del peso chileno, evitándole ajustes traumáticos y dándole tiempo al sector empresarial para incrementar su productividad y reacomodarse en la nueva situación, a fin de mantener el dinamismo del sector exportador.

En la aplicación de la política cambiaría descrita sobresalen tres elementos fundamentales:

i) la existencia de una amplia banda anunciada de notación; ii) el paso de la banda a una canasta de monedas, a! diferencial de inflación interna e internacional $\mathrm{y}$, posteriormente, a una apreciación tendencia! del peso chileno; y iii) la posibilidad de intervenciones del Banco Central al interior de la banda, a través del denominado mecanismo de "flotación sucia". ${ }^{22}$

La política cambiaría se llevó a cabo mediante un sistema de banda anunciada, dentro de la cual se posiciona el tipo de cambio de mercado. La amplitud de dicha banda se incrementó a $\pm 10 \%$ en torno al centro de ella. Dicho centro, definido como el tipo de cambio "acuerdo", se determina sobre la base de una canasta de monedas, ${ }^{\text {a }}$ cuyas ponderaciones reflejan la importancia relativa de las áreas del dólar estadounidense, el marco alemán y el yen japonés en las transacciones comerciales externas de Chile. Dicha paridad central se reajusta diariamente por la inflación interna del mes anterior menos una estimación de la inflación internacional relevante para Chile. ${ }^{24}$ A fines de 1995 se incluyó un descuento adicional de 2\% anual, sobre la base del diferencial de productividad de

\footnotetext{
${ }^{22}$ El objetivo de estas intervenciones era aumentar o disminuir las fluctuaciones transitorias del tipo de cambio, pero no quebrar tendencias.

${ }^{23}$ La vinculación del peso a una canasta de monedas, en lugar de ligarlo sólo al dólar, permitió, de un lado, independizar en mayor medida la política monetaria chilena de la de los Estados Unidos, y, de otro lado, introducir mayor incertidumbre de corto plazo en el tipo de cambio peso/dólar (a diferencia del tipo de cambio peso/ canasta), lo que era funcional al objetivo de desincentivar el arbitraje de tasas de interés.

${ }^{24}$ En consecuencia, la paridad central para la canasta se anuncia con un mes de anticipación, para todos los días del mes siguiente, mientras que la paridad central peso/dólar, peso/marco y peso/yen se anuncia diariamente, en la medida que se conocen las paridades de las principales monedas en los mercados internacionales.
} 
Chile con sus principales socios comerciales, lo que implicaba una progresiva apreciación del peso, la que respondió a cambios estables de la inserción de la economía chilena en la internacional. ${ }^{25}$

La justificación del mecanismo de banda cambiaría en torno a una paridad central radica en el convencimiento de que el tipo de cambio de equilibrio de largo plazo es un concepto dinámico, al cual hay que darle cierta flexibilidad, y también de que los agentes económicos no cuentan en todo momento con la adecuada información y elementos de juicio como para determinar el tipo de cambio real de equilibrio. Esta visión lleva implícita la necesidad de que la autoridad proporcione cierta orientación respecto al nivel del tipo de cambio real que se estima coherente con el equilibrio externo de la economía en el mediano plazo: este es justamente el papel que desempeña el tipo de cambio "acuerdo", al centro de la banda cambiaría, por dos motivos principales. De un lado, porque el mercado, sobre todo cuando los flujos financieros de corto plazo son muy importantes, puede tender a un tipo de cambio real considerablemente alejado (un outlier) del de equilibrio a mediano y largo plazo. De otro lado, porque se postula que en la medida en que la economía se aleje en forma importante y por mucho tiempo del tipo de cambio real de equilibrio, se tenderán a producir desequilibrios mayores, con negativas consecuencias sobre el funcionamiento y desempeño de la economía.

También se estimó conveniente dar cierta estabilidad cambiaria al sector exportador. La dificultad de predecir con exactitud cuál es el tipo de cambio real de equilibrio, la probabilidad de que éste se desalinee respecto de los equilibrios macroeconómicos básicos y la necesidad de dar mayor autonomía y flexibilidad a la política monetaria, sobre todo dada la creciente inserción de la economía chilena en los mercados financieros internacionales, justifican la aplicación de una banda amplia de fluctuación. Ella permite además que, dentro de ciertos parámetros, el mercado desempeñe un papel más importante en la determinación de

\footnotetext{
${ }^{25}$ En efecto, entre los años 1990 y 1996, el nivel de actividad económica en Chile se expandió a una tasa media anual de $6.8 \%$, mientras que la producción mundial lo hizo en $3.1 \%$. En ese mismo período, en Chile la productividad media del trabajo se elevó a una tasa inedia anual en torno al $4.7 \%$, mientras que la productividad total de los factores creció alrededor de $2.3 \%$ anual. Como consecuencia del mayor crecimiento de la productividad, la competitividad internacional se incrementó, lo que en definitiva se tradujo en una expansión de las exportaciones y también en un fortalecimiento del peso chileno. El ajuste por diferencial de productividad en la regla cambiaria sugiere que esta situación continuará a futuro.
}

la posición observada del tipo de cambio al interior de dicha banda, reflejando el criterio de gradualidad antes mencionado.

En el quinquenio estudiado se modificó la banda cambiaria en dos ocasiones, permitiendo de hecho una caída del tipo de cambio acuerdo. Ello se debió a la necesidad de adecuar el valor referencial del tipo de cambio de equilibrio de mediano y largo plazo a las nuevas condiciones estructurales en que se desenvolvía la economía chilena. En efecto, el Banco Central, enfrentado a una creciente afluencia de divisas proveniente tanto de una evolución muy favorable de las exportaciones como de una significativa afluencia de inversión extranjera y de financiamiento internacional, actuó con prudencia y modificó el centro y la amplitud de la banda sólo cuando estuvo convencido de que el tipo de cambio de equilibrio de largo plazo no estaba adecuadamente reflejado en el tipo de cambio acuerdo vigente. Así por ejemplo, el comportamiento registrado y previsible de las exportaciones no tradicionales, el monto del déficit en la cuenta corriente de la balanza de pagos, el incremento de la inversión extranjera hacia y desde Chile, junto a la creciente unificación cambiaria y liberalización de la salida de capitales, al mejoramiento de los indicadores de solvencia externa y a la profundización del mercado chileno de divisas, fueron los principales elementos que influyeron en la decisión de dar lugar a una gradual apreciación del peso chileno. ${ }^{26}$

Cabe señalar que la apreciación real que registró el peso durante los años noventa, en torno al $4.5 \%$ anual, fue el resultado de un proceso de equilibrio que respondió a cambios estructurales experimentados por la economía chilena durante los últimos años, y no a una manipulación del tipo de cambio con el objeto de reducir artificialmente el ritmo inflacionario, Muy por el contrario, un objetivo prioritario de las políticas eco-

\footnotetext{
${ }^{26}$ Sin embargo, cabe mencionar que en los años noventa se dio una tendencia generalizada a la apreciación de las monedas de ios principales países latinoamericanos, fenómeno del que no estuvieron ausentes varios países de Europa central y oriental, debido a causas de orden internacional. Entre ellas cabe destacar las tasas de interés relativamente bajas en los países industriales, el menor riesgo-país de los países que llevaron a cabo reformas estructurales de sus economías, así como las decisiones de importantes inversionistas institucionales de los países desarrollados de diversificar su cartera, internacionalizándose. Lo anterior significó un renovado impulso de la inversión extranjera directa en los sectores productivos y en la inversión de cartera, así como de la afluencia de financiamiento externo de más corto plazo hacia los países de la región. Todo esto contribuyó a la apreciación de las monedas latinoamericanas (con una interrupción, relativamente breve, derivada de la crisis mexicana de fines de 1994).
} 
nómicas implementadas en ese período fue, precisamente, evitar una apreciación artificial del peso. ${ }^{27}$

En efecto, la ya mencionada reinserción de Chile en la economía internacional; el comportamiento de sus exportaciones y de la cuenta corriente de la balanza de pagos; los fuertes aumentos en !as diferencias de productividad, sobre todo del sector transable de la economía, en relación con los principales socios comerciales de Chile, y la sobredepreciación del peso en la segunda mitad de los años noventa (para enfrentar la aguda y extrema escasez de divisas de esa época), eran todos factores que apuntaban a la necesidad de permitir que el tipo de cambio reflejara la mayor fortaleza del peso.

Enfrentadas a dicha necesidad, las autoridades del Banco Central sostuvieron que la mencionada apreciación del peso era un reconocimiento a la consolidación de diversos cambios estructurales en la economía chilena durante los últimos años, los cuales implicaban que el tipo de cambio de equilibrio era inferior al valor vigente del tipo de cambio acuerdo. En términos más generales, los avances en la inserción comercial y financiera de Chile en la economía internacional justificaban una modificación del tipo de cambio de equilibrio de mediano y largo plazo. Entre los cambios estructurales que el instituto emisor mencionó como relevantes cabe destacar: la reducción de los niveles del endeudamiento externo relativo, de un promedio de $106 \%$ del PIB en el trienio 1985-1987 a 35\% en 19941996; la acumulación de reservas internacionales, que en 1994-1996 duplicaron su valor como porcentaje de las importaciones de bienes y servicios respecto del trienio 1985-1987, llegando a representar en un año más de 15 meses de importaciones; el sostenido crecimiento de las exportaciones, que en términos reales en el trienio 1994-1996 alcanzaron un incremento medio anual de $11.6 \%$, superior al ya elevado $9 \%$ registrado en 1985-1997; y, por último, el moderado nivel de ahorro externo que ha necesitado la economía chilena (1.7\% del PIB en 1994-1996, inferior a la cota mínima establecida y muy inferior al $6.3 \%$ de déficit en cuen-

\footnotetext{
${ }^{27}$ Comparaciones internacionales respecto de la apreciación real de !a moneda chilena demuestran que el tipo de cambio real en Chile ha sido uno de los mus estables y menos depreciados de América Latina, a pesar de haberse materializado entradas de capital a toda la región durante el primer quinquenio, previo a la crisis mexicana, de los años noventa. En efecto, de acuerdo a metodología uniforme del Fondo Monetario Internacional (FMI), mientras la apreciación real de la moneda en el período 1990-1994 alcanzó en Chile a 13\%, en Argentina a $63 \%$, en Colombia a 2Í $\%$, en México a $18 \%$ y en Brasil a $17 \%$.
}

ta corriente de la balanza de pagos registrado en 19851987).

Por último, es fundamental comprender que el Banco Central resistió la presión a la baja del precio de la divisa mediante el uso de diversas medidas, entre las que destaca la masiva compra de reservas internacionales, que se analiza en la siguiente subsección.

\section{La política de reservas internacionales}

La política de reservas internacionales aplicada por el Banco Central durante el primer quinquenio de los años noventa tuvo dos objetivos principales: ${ }^{28}$ de un lado, permitir una creciente integración de Chile a la economía mundial, sin mayores riesgos derivados de cambios en las economías de los principales países industriales ni de la volatilidad que suele caracterizar el comportamiento de algunos agentes acreedores internacionales; ${ }^{29}$ de otro lado, mediante la adquisición o venta de divisas, neutralizar en parte el impacto de corto plazo de las entradas y salidas de capital sobre el tipo de cambio.

El primer objetivo se logró principalmente gracias a las cuantiosas reservas internacionales de Chile, uno de los determinantes para que éste fuera calificado como país de bajo riesgo para la inversión internacional; dicha calificación estimuló la inversión externa directa en el país, a la vez que redujo el costo del financiamiento externo ofrecido a Chile. Además, la significativa acumulación de reservas por parte del Banco Central en esos años ${ }^{30}$ le otorgó a Chile una gran fortaleza externa, la que quedó de manifiesto sobre todo a comienzos de 1995, cuando la economía chilena se

\footnotetext{
${ }^{28}$ También hubo avances muy importantes en el manejo de activos y pasivos internacionales, orientados a mejorar la posición financiera neta del Banco Central.

${ }^{29}$ Una elevada acumulación de reservas internacionales es una condición necesaria para que un país pequeño se integre sólida y eficazmente a la economía internacional, y parte de los costos de dicha acumulación puede interpretarse como la prima de un "seguro" para que dicha integración sea efectiva y no genere mayores sobresaltos.

${ }^{30}$ Mientras que a fines de los años ochenta las reservas internacionales alcanzaban para cinco meses de importaciones, en $1994 \mathrm{cu}-$ brían quince meses de compras externas, Asimismo, mientras en 1989 las reservas internacionales netas alcanzaban a un $10.5 \%$ del PIB, en 1994 fueron levemente inferiores a un 26\% del PIB. ES importante señalar asimismo que, a nivel agregado, ni el sector público ni el sector privado no financiero tuvieron pasivos externos de corto plazo significativos, y que los pasivos externos netos de corto plazo de la banca fueron de alrededor de un $4 \%$ del PIB, por lo que la posición neta del país en cuanto a activos internacionales líquidos era muy sólida.
} 
vio afectada mínimamente, ${ }^{31}$ y por muy corto tiempo, por las turbulencias de los mercados financieros internacionales con posterioridad a la crisis cambiaria mexicana de fines de 1994. Por último, la holgada situación de reservas internacionales permitió utilizar una parte de dichas reservas, sin comprometer la liquidez ni mucho menos la solvencia externa del país, para prepagar toda la deuda externa pendiente del refinanciamiento de la crisis de comienzos de los años ochenta, así como el saldo deudor con el FMI. ${ }^{32}$

El segundo objetivo se logró mediante la adquisición o venta de divisas por parte del Banco Central, que se acompañó de una operación de mercado abierto que neutralizaba los efectos monetarios de las operaciones de cambio, lo que se conoce como intervenciones esterilizadoras en el mercado cambiario. De hecho, en el primer quinquenio de los años noventa la mayor parte del tiempo el tipo de cambio estuvo bastante cerca del piso de la banda, cuando no en el piso mismo. Más allá de las compras de divisas impuestas por la propia mecánica de la banda, la política del Banco Central fue esperar un tiempo prudencial para poder distinguir si la afluencia de divisas era de carácter más permanente o transitorio. Si prevalecía esta última hipótesis, ante una entrada de capitales de corto plazo que prontamente pudiera revertirse el Banco Central procedía a adquirir dichas divisas, acumulando reservas internacionales para reducir la volatilidad del tipo de cambio. Algo similar ocurría en el caso de una salida de capitales transitoria. De tratarse de una entrada o salida de capital más permanente, el Banco Central en muchas ocasiones intervino en el mercado cambiario, acumulando o desacumulando reservas, no con el objeto de contravenir de manera sistemática las fuerzas del mercado, lo que sería a la larga insostenible, sino que para hacer gradual en el tiempo el probable ajuste de precios relativos requerido.

La ya señalada apreciación del peso se produjo a pesar del significativo esfuerzo de acumulación de reservas internacionales que realizó el Banco Central:

\footnotetext{
${ }^{31}$ Cabe señalar que si bien el Banco Central hizo esfuerzos significativos para aumentar la rentabilidad asociada a las reservas internacionales, no debe olvidarse que éstas no son mantenidas con un criterio exclusivo de rentabilidad, sino que también como una precaución ante perturbaciones externas inesperadas, a fin de tener suficiente liquidez internacional para enfrentarlas adecuadamente.

${ }^{32}$ El prepago de deuda externa contribuyó a reducir el déficit asociado a la existencia de un diferencial de tasas de interés entre las reservas internacionales y la deuda externa, así como a mejorar aún más los índices de solvencia externa del país, reduciendo el riesgopaís y mejorando las condiciones de acceso del sector privado chileno al crédito internacional.
}

entre 1990 y 1996 el acervo de reservas internacionales se incrementó en 9450 millones de dólares, lo que equivale a poco menos de $4 \%$ del PIB anual. Este acervo de reservas internacionales, que en términos relativos se ubicó entre los más altos del mundo, ha derivado en un costo patrimonial importante para el Banco Central, ${ }^{33}$ pero sin duda contribuyó a una eficiente y fluida integración de Chile a la economía internacional, a atenuar el ritmo de apreciación del peso chileno $\mathrm{y}$, dentro de la política de gradualidad comentada, a un reacomodo poco traumático del precio de los bienes transables en relación al de los bienes no transables de la economía chilena.

\section{La política de cuenta de capitales de la balan- za de pagos}

En una economía pequeña y abierta como la chilena, una mayor integración financiera con el exterior reporta importantes beneficios que deben ser aprovechados. Entre ellos cabe mencionar la disponibilidad de ahorro externo para el financiamiento de la inversión; la absorción de choques transitorios en materia de términos de intercambio y la diversificación del riesgo y de las fuentes de ingreso nacional, todo lo cual permite suavizar la trayectoria del consumo y aprovechar mejor las ventajas comparativas a través de una más profunda inserción internacional del país.

Sin embargo, una mayor apertura financiera también conlleva riesgos que deben ser considerados. Hay costos permanentes y costos de transición. La pérdida de grados de libertad en el manejo de la política monetaria y los efectos desestabilizadores que pueden generar los movimientos de capital en una economía pequeña son costos permanentes de una mayor apertura financiera. Los riesgos asociados a la trayectoria del ajuste desde una cuenta de capitales históricamente cerrada ${ }^{34}$ a una cuenta de capitales abierta súbitamente, son costos de transición.

\footnotetext{
${ }^{33}$ La intervención esterilizada del Banco Central le ha significado costos importantes, dada la mayor (asa de interés que debe pagar por la deuda interna que emite en relación al rendimiento que devengan los activos internacionales que adquiere. Al mismo tiempo, la apreciación real del peso ha deteriorado el valor real de estos activos denominados en moneda extranjera, incluido el crédito al fisco, en relación al de los pasivos internos del instituto emisor. Así, esta política ha tenido como efecto generar un mayor déficit cuasifíscal del Banco Central, el que ha sido conjurado mediante el correspondiente superávit fiscal.

${ }^{34}$ Históricamente los flujos de capitales desde y hacia Chile se encontraban muy restringidos. Tras el abandono de la convertibilidad del peso se instauraron masivos controles sobre las salidas de capital. Si bien a través del tiempo estos controles fueron modificados,
} 
Las condiciones de acceso al financiamiento externo, que fueron muy restringidas para la región después de la crisis de la deuda, cambiaron rápida y significativamente en los años noventa. Una mejor percepción del riesgo-país, las bajas tasas de interés en los países industrializados y una expansión generalizada de los flujos de capital destinados a las llamadas economías emergentes, elevaron en forma significativa la oferta de fondos externos. En forma bastante repentina, países como Chile se encontraron en una situación en que la rentabilidad interna del capital superaba al costo externo de fondos, ajustado por el riesgo-país ${ }^{35}$ y por los cambios en las expectativas respecto del tipo de cambio.

En el pasado esa situación podía mantenerse en el tiempo o cambiar sólo gradualmente, en la medida que la percepción del riesgo-país y la desconfianza en las monedas locales limitaban el arbitraje internacional de fondos. A comienzos de los años noventa, en cambio, un escenario de apertura financiera irrestricta habría incentivado la afluencia en poco tiempo de cuantiosos recursos financieros de corto plazo, desestabilizando el gasto, el precio de los activos y precios claves como la propia tasa de interés, los salarios y el tipo de cambio real.- ${ }^{16} \mathrm{El}$ curso que seguiría la

el espíritu de las restricciones se mantuvo, excepto por períodos intermitentes de mayor liberalidad. En cuanto a las entradas de capital, las limitadas condiciones de acceso al financiamiento externo las restringían en forma natural. De hecho, no fue sino hasta los años setenta que las economías en desarrollo, y entre ellas Chile, lograron renovar el acceso masivo al financiamiento externo que habían perdido tras la Gran Depresión. Pero para Chile esto duró sólo un corto período, pues la crisis internacional de la deuda a comienzos de los años ochenta, junto al alto nivel de endeudamiento extemo que acumuló el país en ese breve lapso, llevaron a suspender una vez más el acceso al financiamiento internacional.

${ }^{35}$ Este diferencial de rentabilidad obedece a circunstancias históricas y a reformas estructurales que han afectado la productividad de ¡a economía chilena, y que poco tienen que ver con la política monetaria. En efecto, considerando la dotación relativa de capital y recursos humanos en Chite, el limitado acceso al financiamiento extemo que tenía su economía hasta hace poco, y las bajas tasas históricas de ahorro e inversión internas, es natural que la rentabilidad interna del capital productivo, que debe distinguirse de la rentabilidad del capital financiero, tienda a ubicarse por encima de la que se observa en las economías industrializadas.

${ }^{36}$ Además, en cuanto a las instituciones del sector financiero, una apertura precipitada, sin que se haya generado la regulación y supervisión adecuadas de los propios intermediarios financieros y de la autoridad correspondiente, puede y suele generar problemas de magnitud. Chile tuvo experiencias previas en que, por no contar con dicha regulación, hubo incentivos perversos en el sector financiero, que luego se transmitieron al resto de la economía. Cabe recordar que en este sector hay riesgos sistémicos involucrados, por lo que actuar con prudencia en relación a él es de la mayor importancia. economía, si se validara esa tendencia, es bien conocido. Dada la magnitud de los flujos, la primera etapa del proceso de transferencia es de auge, aumenta el precio de los activos y los salarios suben, se incrementan el consumo y la inversión, se aprecia el tipo de cambio y se abaratan las importaciones. Esta etapa es de difícil manejo macroeconómico, ya que es necesario contener las presiones inflacionarias que se generan en los mercados internos, y estar atentos para evitar la creación de burbujas financieras, que acentưan aún más el movimiento de precios fuera de su trayectoria de equilibrio así como la llegada de recursos financieros aún mayores. Sin embargo, la fase de expansión del ciclo siembra las semillas de la fase de contracción. En efecto, a medida que crece el déficit en cuenta corriente de la balanza de pagos y se acumulan pasivos externos, la percepción de riesgo-país comienza a aumen$\operatorname{tar}^{37}$ y la disponibilidad de fondos externos se reduce, el volumen de transferencias externas disminuye y, por lo tanto, los precios y el gasto deben iniciar su trayectoria de vuelta.

En el escenario ideal, los flujos de entrada se revierten gradualmente en el tiempo y los ajustes en los precios claves son suaves y no generan desequilibrios importantes en el desempeño de la economía. Sin embargo, el escenario más probable y realista es aquél en que las entradas de capital se detienen e incluso se revierten abruptamente, provocando un ajuste traumático. En efecto, la economía se encuentra en una posición muy vulnerable cuando exhibe un alto nivel de endeudamiento externo y un déficit significativo en la cuenta corriente, más aún si el financiamiento externo es de corto plazo. Alzas en las tasas de interés internacionales, caídas en los términos de intercambio o, simplemente, cambios de expectativas externas o internas, pueden gatillar una repentina crisis de confianza que ponga abrupto término al proceso de transferencia externa de recursos. La crisis de la deuda externa de la región en los años ochenta y las turbulencias en los mercados financieros internacionales a fines de 1994 y en 1995 ilustran muy bien estos riesgos.

En este último escenario, el ajuste requerido involucra una peligrosa combinación de altas tasas de interés internas, caída en el precio de los activos internos y fuerte depreciación en el tipo de cambio real, lo que inevitablemente trae consigo problemas de importancia en los mercados financieros internos e indu-

\footnotetext{
${ }^{37}$ Históricamente, este proceso ha tomado bastante tiempo en concretarse.
} 
ce presiones inflacionarias adicionales; de otro lado, y no menos importante, cabe esperar un aumento significativo en el desempleo y una baja en el nivel de actividad económica, producto de las fricciones que se introducen en los mercados financieros y laborales, así como de la brusca disminución del nivel de gasto. La experiencia de Chile a principio de los años ochenta, y también la de otros países de la región, ha probado que este escenario pesimista no sólo es muy probable, sino que suele acarrear costos muy significativos por largo tiempo. Es por ello que en los años noventa, para mantener y consolidar la disciplina macroeconómica y el equilibrio externo, se optó por realizar una apertura prudente de la cuenta de capitales, minimizando los riesgos de una trayectoria indeseable de ajuste que pudiera poner en peligro los avances ya logrados.

Desde el ángulo del equilibrio interno, cabe también destacar el rol de la tasa de interés y su vínculo con la modalidad y velocidad de la apertura financiera externa. En efecto, para lograr un nivel y ritmo de crecimiento del gasto interno compatibles no sólo con el uso prudente del ahorro externo, sino que además con e! potencial productivo de la economía chilena, era necesario que las tasas de interés internas se ubicaran por encima de las que prevalecieron en las principales economías industrializadas durante el primer quinquenio de los años noventa. ${ }^{38}$

Puesto en otros términos, dado el bajo riesgo-país y las nulas expectativas de devaluación (o, para ser más precisos, positivas expectativas de revaluación) del peso chileno, la tasa de interés internacional, ajustada por ambos efectos, era muy inferior a la tasa de interés interna requerida para el equilibrio macroeconómico interno y externo. El dilema que enfrentó el Banco Central era cómo cerrar dicha brecha, para no generar presiones inflacionarias adicionales a las programadas y/o sobre el déficit en la cuenta corriente de la balanza de pagos. Cabe recordar que este dilema debía enfrentarse en condiciones de ahorro fiscal y superávit público positivos, de una importante acumulación de reservas internacionales (que estaba generando un significativo déficit cuasifiscal), así como de una tendencia a una fuerte apreciación del peso chileno.

En vista de las consideraciones anteriores, el objetivo de la política de cuenta de capitales fue comple-

\footnotetext{
${ }^{38}$ La tasa de interés debe tener cierta coherencia con la rentabilidad del capital productivo. Con el tiempo, tasas de inversión elevadas como las que se han observado en Chile, y aumentos adicionales en el ahorro interno, permitirán ir achicando la diferencia entre tasas de interés externas c internas.
}

mentar las políticas fiscal, monetaria, cambiaría y de reservas internacionales, para impedir que por la vía de una afluencia "excesiva" de divisas se atentara contra los equilibrios interno y externo. Puesto de otro modo, si las políticas fiscal, monetaria, cambiaria y de reservas internacionales estaban bien formuladas y ejecutadas, y si seguían entrando flujos financieros de corto plazo, ${ }^{39}$ era indispensable frenar la velocidad del ingreso neto de capitales, para evitar que aumentara la inflación y/o el déficit en la cuenta corriente de la balanza de pagos. Por esto se decidió avanzar hacía una mayor integración financiera con el resto del mundo, pero con una prudencia, un ritmo y una selectividad que fueran coherentes con ese objetivo.

Dicha política se aplicó mediante diversos mecanismos. De un lado, en el primer quinquenio de los años noventa se liberalizó significativamente la salida de capitales. ${ }^{40}$ En efecto, no sólo los exportadores pudieron disponer con completa libertad del total de sus retornos, sin obligación alguna de ingresarlos al país, sino que además se tomaron medidas liberalizadoras en diversos ámbitos. ${ }^{41}$ Así por ejemplo, se redujo de tres años a un año el plazo mínimo para la repatriación de capital ingresado por no residentes y se autorizó la emisión de bonos y acciones en el exterior (ADR), cuyas exigencias fueron relajándose gradualmente a lo largo del tiempo. De otro lado, se liberalizó totalmente la salida de inversiones en virtud de la conversión de deuda externa (mecanismo vinculado a la crisis de comienzos de los años ochenta) y se liberalizó el prepago de deudas al exterior, así como el porcentaje mínimo de crédito externo que debía acompañar a la inversión externa directa.

\footnotetext{
${ }^{3 g}$ Es conveniente distinguir entre una afluencia de divisas originada en un muy buen resultado de las exportaciones y de la entrada neta de inversión externa directa de mediano y largo plazo, que de por sí explican una apreciación equilibrada del peso, de la entrada de financiamiento externo, por lo general de muy corto plazo, determinado básicamente por el estímulo de arbitrar el diferencial de tasas de interés anotado.

${ }^{40}$ Cabe señalar que la creciente apertura a la salida de capitales se relaciona con la estrategia de desarrollo y de inserción de la economía chilena en la economía internacional, No es su objetivo, y hasta puede generar el efecto contrario, intentar incrementar el valor de la divisa.

${ }^{41}$ Además de dar total libertad en el manejo de los retornos de exportación, hubo una serie de medidas vinculadas a la cuenta corriente de la balanza de pagos, entre otras, una importante rebaja arancelaria (desde $15 \%$ a $11 \%$ ) y varios acuerdos de libre comercio, orientadas hacia una creciente integración de los denominados mercados cambiarios formal e informal, todo lo cual contribuyó a profundizar durante el período la integración comercial y financiera de Chile en la economía mundial.
} 
Complementando lo anterior, y en lo que fue una medida de gran significación, se liberalizó completamente la inversión de las personas y empresas chilenas en el exterior, permitiéndoles así diversificar de mejor manera sus riesgos. Además, se fueron adoptando medidas tendientes a promover una mayor diversificación internacional de la cartera de activos de los inversionistas nacionales, especialmente de los institucionales. Estos últimos fueron las únicas excepciones en cuanto a la liberalización total, pero no en cuanto a darles cada vez más opciones en el exterior. La apertura de los bancos, los fondos de pensiones, las compañîas de seguros y los fondos mutuos al exterior también se llevó a cabo, aunque menos rápidamente que para todo el resto de los agentes económicos, en parte por restricciones legales y, para las tres primeras, por consideraciones prudenciales vinculadas al riesgo sistémico y a compromisos fiscales contingentes.

La entrada de capitales se fue abriendo gradual y selectivamente, desincentivando la de más corto plazo. Esta política gradual se justifica por e! propósito no sólo de evitar desequilibrios externos de magnitud, sino también de posibilitar un cambio de precios relativos que permita a los diferentes sectores efectuar ajustes menos traumáticos a través del tiempo. La apertura selectiva lleva a imponer ciertos controles específicos, de ser necesario. Si bien la tendencia consistió en ir relajando en forma paulatina los desincentivos a las entradas de capital, ello se complementó con acciones que apuntaron a una mayor selectividad de los ingresos de capital, para reducir la exposición a la volatilidad de los flujos financieros de corto plazo, otorgar más autonomía a la política monetaria y frenar la creación de burbujas en los mercados bursátil y de renta fija de más largo plazo. Con estas últimas medidas se intentó encarecer la entrada de capitales, en particular la de más corto plazo, restringir su volumen global, mejorar su "calidad" y alargar los plazos del financiamiento externo de Chile.

De un lado, al reducir de tres a un año la restricción $^{42}$ para la repatriación del capital de las inversiones directas, se desincentivó la llegada de flujos al mercado bursátil, lo que contribuyó a no generar una burbuja de precios en dicho mercado.

De otro lado, se moderó la velocidad a la cual las empresas chilenas podían obtener crédito o capital en

\footnotetext{
${ }^{42}$ Lo que, como se señaló, constituyó una liberalización respecto de la situación vigente a fines de los años ochenta.
}

el exterior. En efecto, para la colocación externa tanto de bonos como de acciones se exigieron montos mínimos y el cumplimiento de ciertos requisitos, determinados por empresas clasificadoras de riesgo internacional y asociados a la solvencia de las empresas o de jos instrumentos que éstas deseaban colocar internacionalmente. ${ }^{41}$ Por esta vía se contribuyó a limitar el número de empresas y la velocidad a la que podían captar recursos financieros en los mercados internacionales, lo que ayudó a impedir entradas excesivas de divisas al país. ${ }^{44}$

En tercer lugar, se impuso un encaje no remunerado, por el plazo de un año, al crédito y otras fuentes de financiamiento externo, de modo de encarecer el costo de ingresar capitales de corto plazo. Por esta vía se intentó dar mayor espacio y autonomía a la política monetaria, de modo que idealmente todos los agentes económicos enfrentaran la misma tasa de interés, definida por el Banco Central para lograr el equilibrio interno, a la vez que se buscó frenar la especulación y la volatilidad inherentes a los llamados capitales "golondrinas", así como reducir la posibilidad de arbitraje de tasas de interés.

Desde una perspectiva más general, el conjunto de políticas orientadas a efectuar una apertura financiera gradual y selectiva permitió cambiar la estructura o composición de las acreencias externas sobre Chile, incrementándose la participación del capital de riesgo en relación al endeudamiento externo y, dentro de este último, el de largo plazo en relación al de corto plazo. Esto contribuyó a reducir la vulnerabilidad de la economía chilena ante los vaivenes de la economía mundial, el comportamiento procíclico que suelen tener los titulares de deuda externa y los cambios en las expectativas de los agentes económicos internacionales.

Aunque otros países de la región llevaron a cabo políticas formalmente más "liberales o aperturistas" que las de Chile en cuanto a la cuenta de capitales de la balanza de pagos, en ellos las tasas de interés internas fueron más altas que las chilenas, y tuvieron mayores diferencias con las tasas de interés internacionales. Esta situación, que aparentemente debió ser a

\footnotetext{
${ }^{43}$ Dichos montos y requisitos también fueron relajándose gradualmente, sin eliminarse por completo.

${ }^{44}$ Otra ventaja de dicha estrategia, considerando que antes de 1990 no había empresas chilenas activas en los mercados internacionales de bonos 0 acciones, es que por la solvencia y seriedad de las primeras empresas en salir, se generaba una externalidad positiva para las que salieran posteriormente. Una desventaja de esta medida es que ella, en la práctica, favorece a las empresas "grandes" más que a las empresas pequeñas y a las personas.
} 
la inversa, se explica principalmente por el mayor riesgo-país o de devaluación que enfrentaban aquellos países. Por lo tanto, no es obvio que por llevar a cabo con rapidez una apertura financiera total un país se vaya a integrar efectivamente en forma sólida y permanente a los mercados internacionales de capital. En síntesis, un país no está "más integrado" a la economía internacional por ser más o menos liberal, sino por la cantidad, el costo, la calidad y la permanencia en el tiempo de la transferencia de capitales efectivamente disponibles para él, elementos todos que suelen asociarse a la confianza que el resto del mundo deposita en esa economía. ${ }^{45}$
Finalmente, hay quienes sostienen que el buen desempeño macroeconómico de Chile en los primeros años del decenio de 1990 se debió a su elevado nivel de ahorro interno, más que a la estrategia macroeconómica. Cabe señalar, sin embargo, que el ahorro interno no es una constante, independiente de dicha estrategia. Los estudios empíricos y la experiencia sugieren más bien que políticas "ingenuas" con relación a la entrada de financiamiento externo suelen llevar a que el ahorro externo, que en muchas ocasiones está concentrado en el muy corto plazo, financie un exceso de gasto de consumo interno y sustituya el ahorro interno.

\section{VI}

\section{Algunas conclusiones}

El principal dilema de la política macroeconómica de los años noventa fue que el equilibrio interno requería que la tasa de interés en Chile fuese bastante superior a la de los países industriales, en tanto que a la vez el riesgo-país disminuía sistemáticamente y predominaban expectativas de revaluación del peso chileno. Considerando que el sector público registró un superávit de $1.8 \%$ como promedio anual, que la acumulación de reservas estaba generando un costo cuasifiscal significativo, que se liberalizó muy fuertemente la salida de capitales y que el peso se apreció más de $4 \%$ real anual (a pesar del esfuerzo del Banco Central por desestimular dicha situación), la política macroeconómica tuvo que enfrentar la siguiente disyuntiva: permitir una rápida igualación de la tasa de interés interna con la internacional, o cerrar, parcialmente al menos, dicha brecha. Lo primero habría sido esencialmente contradictorio con la estrategia global y habría conducido a un gasto excesivo, a una mayor inflación y/o a una apreciación adicional del peso y a un abultado déficit

\footnotetext{
${ }^{45}$ Desde una perspectiva macroeconómica, podría parecer más fácil y probablemente también más necesario ser más "liberal" cuando la percepción internacional de riesgo-país es alta. En esas condiciones la diferencia natural de intereses con el exterior, ajustada por el riesgo-país y por expectativas de devaluación, proporciona suficiente espacio para manejar una política monetaria independiente y se evitan los efectos desestabilizadores descritos anteriormente. Sin embargo, sería absurdo concluir que lo deseable es que haya una percepción de riesgo-país más alta, ya que es muy beneficioso ser confiable y creíble y contar por esa vía con una amplia y poco costosa disponibilidad de financiamiento externo.
}

en la cuenta corriente de la balanza de pagos, elevando la vulnerabilidad externa. En consecuencia, la política que se siguió fue la de reducir la diferencia de tasas de interés mediante una graduación de la velocidad a la que las empresas radicadas en Chile podían ingresar financiamiento externo, y a la vez encarecer la entrada de capitales de corto plazo para desíncenti varia.

En el quinquenio 1992-1996 el PIB creció a un ritmo medio anual de $7.5 \%$ y la tasa de desempleo fue de $7 \%$. Las remuneraciones reales aumentaron al mismo ritmo que la productividad media del trabajo: $4.7 \%$ anual. La formación bruta de capital fijo se incrementó en $14.2 \%$ anual, más que doblando el ritmo de crecimiento del PIB, y el ahorro interno alcanzó un promedio de $25.1 \%$ del PIB. El superávit fiscal fue de $1.8 \%$ del PIB, mientras que el ahorro fiscal alcanzó al 5.1\% del PIB. La tasa de interés real de colocaciones bancarias entre noventa días y un año fue en promedio de 8.9\% anual. La deuda pública interna (del Banco Central), como porcentaje del PIB, se redujo respecto de los

\footnotetext{
${ }^{46}$ Asimismo, sería un error pensar que la economía chilena ha salido casi intacta del reciente episodio de turbulencias financieras sólo por los desincentivos a las entradas de capitales. Las principales fortalezas se encuentran en factores más estructurales, como el alto nivel de ahorro interno y la coherencia en el diseño y la ejecución de las políticas fiscal, monetaria, cambiaría y de reservas internacionales. Los encajes y las restricciones a la entrada de capitales que permanecen son importantes en la medida que facilitan dicha coherencia. Ellos son una pieza más de un engranaje internamente coherente.
} 
años anteriores y alcanzó a 33.6\%, mientras que su plazo de vencimiento creció de año en año, alcanzando en el quinquenio un promedio de 3.2 años. La inflación anual media fue de $9.7 \%$, la menor tasa registrada para un quinquenio desde hacía más de medio siglo en Chile, y cayó desde $27.3 \%$ en 1990 y $18.7 \%$ en 1991, a un ritmo decreciente muy similar a la meta de inflación anual del Banco Central, hasta 6.6\% a fines de 1996. El peso chileno se apreció a un ritmo anual de $4.3 \%$ real, a la vez que las exportaciones crecieron en términos reales en $10.4 \%$ por año, un ritmo $50 \%$ mayor que el del crecimiento del PIB. El déficit medio anual en la cuenta corriente de la balanza de pagos fue de $2.2 \%$ del PIB. La inversión externa directa hacia y desde Chile alcanzó cifras sin precedentes. La entrada de capitales fue de $6 \%$ del PIB y las reservas internacionales netas equivalieron al $22.4 \%$ del PIB y a un año de importaciones de bienes. La deuda externa representó en promedio $38.1 \%$ del PIB, y $15.7 \%$ descontadas las reservas internacionales.

Estos resultados muestran que en la primera mitad de los años noventa Chile tuvo éxito en combinar crecimiento económico y aumentos en el empleo, la productividad y los salarios, así como en el ahorro y la inversión, logrando a la vez significativos avances en la estabilidad de precios, no sólo sin poner en riesgo los equilibrios en el resto de la economía, sino asegurándolos y consolidándolos (particularmente el que ha sido el talón de Aquiles tradicional de la economía chilena: el equilibrio del sector externo).

Sin embargo, no es coincidencia que se hayan obtenido estos resultados positivos dentro de un mismo período. Estos logros están relacionados entre sí y se refuerzan mutuamente. En efecto, cabe postular una suerte de círculo virtuoso entre estabilidad macroeconómica y crecimiento sostenido. El crecimiento trae estabilidad y la estabilidad trae crecimiento.

Las vías por las cuales se interrelacionan el crecimiento y la estabilidad son múltiples. Así por ejemplo, la consolidación del saneamiento de las finanzas públicas, la regulación prudencial y la estricta supervisión del sistema bancario, unidas a una eficiente asignación de los recursos financieros —derivada en parte de la vigencia de precios macroeconómicos claves no distorsionados-, contribuyeron significativamente a elevar el ahorro financiero y dirigirlo hacia la inversión, evitando la aparición de burbujas financieras, lo que a su vez ayudó a la estabilidad y solvencia del sistema bancario del país; asimismo, los avances y la profundización del mercado de capitales también desempeñaron un importante papel en la provisión de financiamiento interno de largo plazo, factor determinante para al aumento de la inversión.

La mantención de un ambiente de disciplina macroeconómica y de control inflacionario contribuye a crear un ambiente que permite planificar a largo plazo, lo que a su vez eleva también las tasas de inversión y lleva a introducir nuevas tecnologías, que en definitiva generan crecimiento. A su vez, la mantención de un cuadro de crecimiento sostenido garantiza la rentabilidad de las nuevas inversiones y facilita la disciplina fiscal y monetaria. En efecto, por el lado del gobierno, las presiones sobre el presupuesto se reducen cuando el empleo, las remuneraciones y las utilidades de las empresas están creciendo, en tanto que el incremento de los ingresos tributarios permite ir satisfaciendo las necesidades públicas más urgentes, sin poner en riesgo el equilibrio fiscal. Por el lado del Banco Central, la tarea de mantener controlada la inflación también se facilita cuando la economía se encuentra en situación de crecimiento sostenido y bajo desempleo, pues de ser necesario aplicar medidas contractivas habrá un mayor grado de aceptación, lo que a su vez permitirá un ajuste rápido y eficiente.

Está empíricamente demostrado que hay una correlación entre mayor crecimiento económico y aumentos en la tasa de ahorro nacional, no estando clara la causalidad; por su parte, el mayor ahorro interno genera estabilidad, puesto que reduce la vulnerabilidad de la economía frente a perturbaciones externas. En efecto, la mantención de un déficit moderado en cuenta corriente y de favorables índices de solvencia externa permiten un acceso oportuno al financiamiento externo cuando éste es más necesario, por ejemplo, en situaciones desfavorables de la relación de precios del intercambio. De esta forma se reduce el riesgo de tener que enfrentar una crisis externa o tener que aminorar bruscamente el ritmo de crecimiento económico. Por lo demás, un alto nivel de ahorro interno amortigua los efectos sobre la economía de las turbulencias en los mercados financieros internacionales, como las que buena parte de la región debió enfrentar en 1995, debido a la crisis mexicana.

Los círculos virtuosos tienen algo de mágicos: el todo es mayor que la suma de las partes, porque las partes se refuerzan mutuamente. Sin embargo, cuando la tendencia apunta en el sentido contrario, los círculos virtuosos pueden transformarse en círculos viciosos. Por esto es fundamental insistir en la necesidad de acrecentar el ahorro y la inversión, de mantener las condiciones de equilibrio externo, y en especial, de que perseveren en la disciplina macroeconómica todos los agentes involucrados. 
La experiencia chilena del quinquenio considerado aquí, aun siendo muy específica - ya que en política económica no existen los "modelos exportables"-, permite destacar algunos elementos que han sido fundamentales para los resultados que se lograron.

Primero, pone de relieve la necesidad de cuentas fiscales equilibradas, así como de una adecuada coordinación entre las políticas fiscal, monetaria, cambiaría y salarial. El seguimiento y control de la demanda agregada, tanto en su nivel como en su tasa de cambio, es condición necesaria, aunque insuficiente, para lograr con eficiencia los equilibrios interno y externo.

Además, sugiere que las presiones inflacionarias sobre los costos se moderaron sustancialmente gracias a que los trabajadores y empresarios incorporaron paulatinamente la inflación proyectada decreciente que había establecido como meta el Banco Central, a los criterios utilizados tanto en las negociaciones laborales como en la determinación de los precios de los bienes y servicios. La creciente credibilidad del Banco Central tuvo aquí un papel crucial.

El objetivo de atenuar la amplitud del ciclo económico mediante una adecuada anticipación de la política macroeconómica frente a excesos de gasto incipientes y no manifestados y a la comprobación de holguras por el lado de la oferta, también contribuyó a los resultados obtenidos. Al respecto, la experiencia chilena destaca la conveniencia de introducir cierta flexibilidad en la formulación y ejecución de la política económica, para enfrentar de manera oportuna y eficiente los efectos de perturbaciones internas o externas. Dicha flexibilidad fue crucial para distribuir en varios mercados los efectos positivos y negativos de esas perturbaciones, contribuyendo así a un ajuste más equilibrado y sostenible de la economía. A su vez, este mecanismo más equilibrado de reacomodo de los diferentes mercados se retroalimentó con el criterio de que los precios macroeconómicos claves no se desviaran durante un tiempo largo de sus valores de equilibrio de mediano y largo plazo, lo que ha sido determinante para dar estabilidad y sustentabilidad al proceso de crecimiento y desarrollo económico chileno.

Vinculado a lo anterior, la experiencia chilena sugiere ir dando gradualmente al mercado un papel cada vez más importante en la determinación de pre- cios claves como el tipo de cambio y la tasa de interés, comenzando por el segmento de largo plazo del mercado, para ir incorporando paulatinamente al sector privado, a medida que los mercados se profundicen y se vuelvan más transparentes y competitivos, en la formación de los precios de corto plazo.

La preocupación por el déficit en la cuenta corriente de la balanza de pagos como hilo conductor de la estrategia macroeconómica, junto a una trayectoria gradual pero sostenida de metas de inflación decrecientes, fueron el eje operativo de la política macroeconómica chilena. Quizás el mayor desafío del Banco Central durante la primera mitad de los años noventa fue haber enfrentado la enorme afluencia de divisas característica de ese período, cuidando de que tanto el nivel como el crecimiento de la absorción (gasto interno) fuesen compatibles con la baja sistemática y significativa de la inflación, así como con la mantención del déficit en la cuenta corriente de la balanza de pagos dentro de valores muy razonables. Esto último fue decisivo para que se sostuviera la tendencia creciente del ahorro interno, para que éste financiara la mayor parte de la inversión, y para que la economía chilena se integrara en forma más sólida y menos vulnerable, en el plano tanto comercial como financiero, a la economía internacional.

En síntesis, los resultados macroeconómicos del quinquenio 1992-1996 fueron muy satisfactorios. Se logró un elevado crecimiento de la actividad económica y del empleo, del ahorro interno y de la inversión, así como de los salarios reales y la productividad. Al mismo tiempo, se redujo significativamente la inflación, la que va camino a igualarse con la que registran los países industrializados. Y, lo que es de la mayor importancia, lo anterior no sólo se logró sin poner en peligro el equilibrio externo de la economía chilena, sino que se perfeccionó la inserción de Chile en la economía internacional, se crearon sólidas cuentas externas, mejoraron los indicadores de solvencia externa del país y se redujo su vulnerabilidad. Tan importante como lo anterior fue que no se generaron desequilibrios en ninguna otra área clave de la economía, lo que permite mirar con optimismo las posibilidades de avanzar en el desarrollo económico de Chile y profundizarlo. 